\title{
WestVirginiaUniversity
}

THE RESEARCH REPOSITORY @ WVU

Graduate Theses, Dissertations, and Problem Reports

2001

\section{Electrical characterization of thin film nanostructure templates}

Christopher James Garman

West Virginia University

Follow this and additional works at: https://researchrepository.wvu.edu/etd

\section{Recommended Citation}

Garman, Christopher James, "Electrical characterization of thin film nanostructure templates" (2001). Graduate Theses, Dissertations, and Problem Reports. 1191.

https://researchrepository.wvu.edu/etd/1191

This Thesis is protected by copyright and/or related rights. It has been brought to you by the The Research Repository @ WVU with permission from the rights-holder(s). You are free to use this Thesis in any way that is permitted by the copyright and related rights legislation that applies to your use. For other uses you must obtain permission from the rights-holder(s) directly, unless additional rights are indicated by a Creative Commons license in the record and/ or on the work itself. This Thesis has been accepted for inclusion in WVU Graduate Theses, Dissertations, and Problem Reports collection by an authorized administrator of The Research Repository @ WVU. For more information, please contact researchrepository@mail.wvu.edu. 


\section{Electrical Characterization of Thin Film Nanostructure Templates}

Christopher James Garman

Thesis Submitted to

The College of Engineering and Mineral Resources

At

West Virginia University

In partial fulfillment of the requirements for the degree of

Master of Science

In

Electrical Engineering

Biswajit Das, Ph.D., Chair

Lawrence Hornak, Ph.D.

Kathleen Meehan, Ph.D.

The Lane Department of Computer Science and Electrical Engineering

Morgantown, West Virginia

2001 


\section{Abstract \\ Electrical Characterization of Thin Film Nanostructure Templates \\ Christopher James Garman}

An improved apparatus for anodizing aluminum films on Si substrates is presented. In addition, an explanation is given for adapting the system to $\mathrm{SiC}$ and glass substrates. The system presented is optimized for throughput and safety to focus on volume production. MOS capacitors created with the system are analyzed with capacitance-voltage measurement techniques to provide insight into device operation. Ni is deposited into porous alumina templates to create Ni nanostructures. 


\section{Acknowledgements}

I would like to take this opportunity to thank several people, without whom this research would not have been possible. First and foremost, I would like to thank Dr. Biswajit Das, my advisor. His advice has been crucial to my successes, both academic and personal. I also would like to thank Dr. Kathleen Meehan and Dr. Larry Hornak, members of my review committee, who offered many helpful suggestions. My work with capacitance-voltage analysis relied heavily upon the expertise of Carlo DaCunha, who not only created the Labview C-V data acquisition software I used, but also gave extensive help in using the system. I am very grateful to Steve McGinnis and Paul Sines, members of the Nanostructures Research Group at WVU, who were always available to give laboratory assistance and experimentation suggestions. I would like to thank Dustin McIntyre for assistance in building the anodization equipment, and his research group, the Center for Industrial Research Applications, for providing the equipment to do so. Jarod King, from the Lane Department of Computer Science and Electrical Engineering, was very helpful in providing consistent computer support, as well as many productive lunchtime brainstorming sessions. I am grateful to Srikanth Nistala for his help in device fabrication. I would like to thank Rahul Kodkani for his generous assistance in C-V data organization and compilation. David Cushing, of Redpoint Controls, also gave consistent support throughout the project. I would also like to thank the National Renewable Energy Laboratory and the National Energy Technology Laboratory for their financial support of this research.

Finally, I would like to dedicate this work to my fiancée, Mary Jean Masters, and to my parents, James and Paula Garman, all of whom assisted in countless ways. I gratefully acknowledge the remainder of my family for their constant support and encouragement. 


\section{Contents}

1.0 Introduction _ 1

2.0 Development of an Improved Anodization Apparatus _ 5

2.1 Earlier Anodization Apparatus _ 5

2.2 Vacuum Immersion Apparatus ___ 8

2.3 Aperture Exposure Immersion Apparatus___ 11

2.4 Anodization Process __ 14

3.0 Capacitance Voltage Characterization of Templates _ 16

3.1 Theoretical Background ___ 17

3.2 Device Fabrication___ 20

3.3 CV Measurements__ 22

3.4 Results and Analysis __ 23

3.5 Discussion__ 35

4.0 Fabrication of Nickel Nanostructures___ 48

4.1 Electrochemical Deposition of Nickel __ 48

4.2 Deposition Rate Characterization _ 49

4.3 Discussion__ 54

4.4 Synthesis of Nickel Nanostructures _ 54

$5.0 \quad$ Summary and Conclusions ___ 55

6.0 Future Work__ 56

$7.0 \quad$ Bibliography__ 57

8.0 Appendices _ 62

8.1 Appendix A - Capacitance Voltage Data Evaluation Software __ 62

8.2 Appendix B - Pore Geometry Estimation Software __ 65

8.3 Appendix C - Aperture Exposure Immersion Apparatus __ 67

8.3.1 Base Construction __ 67

8.3.2 Faceplate Construction __ 68 


\section{List of Figures}

Figure 1.1 - Schematic Top and Cross-Sectional Views of Pores Formed in Anodized Alumina 1 Figure 1.2 - SEM Top View of Bulk Porous Alumina Showing Highly-Ordered Pores ___ 2 Figure 2.1 - First Anodization Apparatus Developed by NRG __ 6 Figure 2.2 - Vacuum Immersion Apparatus___ 9

Figure 2.3 - Vacuum Immersion Assembly__ 10

Figure 2.4 - Aperture Exposure Immersion Assembly ___ 12

Figure 2.5 - Anodization Setup___ 13

Figure 3.1 - Cross Section of a MOS Capacitor Formed by a Porous Alumina Insulator __ 16

Figure 3.2 - Typical Capacitance Voltage Scan of a P-type MOS device ___ 17

Figure 3.3 - Energy Band Diagrams of a P-MOS Capacitor___ 19

Figure 3.4 - MOS Capacitors with Porous Oxide Layer ___ 20

Figure 3.5 - Schematic Representation of a Single MOS Capacitor __ 21

Figure 3.6 - Probe Station Setup______ 22

Figure 3.7 - Typical Current-Voltage Data for Pore-Widened Samples___ 24

Figure 3.8 - Typical Current-Voltage Data for Samples With No Pore Widening_ 25

Figure $3.9-15 \mathrm{~mA} / \mathrm{cm}^{2}$, Not Pore Widened, $\mathrm{Co}=174 \mathrm{pF} 26$

Figure $3.10-15 \mathrm{~mA} / \mathrm{cm}^{2}$, Pore Widened $3 \mathrm{~min}, \mathrm{Co}=300 \overline{\mathrm{pF}} 27$

Figure 3.11 - Pad Layout, $15 \mathrm{~mA} / \mathrm{cm}^{2}$, Pore Widened $3 \mathrm{~min} \_27$

Figure $3.12-15 \mathrm{~mA} / \mathrm{cm}^{2}$, Pore Widened $6 \mathrm{~min}, \mathrm{Co}=300 \mathrm{pF} 28$

Figure 3.13 - Pad Layout, $15 \mathrm{~mA} / \mathrm{cm}^{2}$, Pore Widened $6 \mathrm{~min} \_28$

Figure 3.14 - $20 \mathrm{~mA} / \mathrm{cm}^{2}$, Not Pore Widened, $\mathrm{Co}=143 \mathrm{pF} 29$

Figure $3.15-20 \mathrm{~mA} / \mathrm{cm}^{2}$, Pore Widened $3 \mathrm{~min}, \mathrm{Co}=260 \mathrm{pF} 30$

Figure 3.16 - Pad Layout, $20 \mathrm{~mA} / \mathrm{cm}^{2}$, Pore Widened $3 \mathrm{~min} \_30$

Figure 3.17 - $20 \mathrm{~mA} / \mathrm{cm}^{2}$, Pore Widened $6 \mathrm{~min}, \mathrm{Co}=300 \mathrm{pF} 31$

Figure 3.18 - Pad Layout, $20 \mathrm{~mA} / \mathrm{cm}^{2}$, Pore Widened $6 \mathrm{~min} \_31$

Figure $3.19-30 \mathrm{~mA} / \mathrm{cm}^{2}$, Not Pore Widened, Co $=178 \mathrm{pF} 32$

Figure $3.20-30 \mathrm{~mA} / \mathrm{cm}^{2}$, Pore Widened $3 \mathrm{~min}$, Co $=70 \mathrm{pF} 33$

Figure 3.21 - Pad Layout, $30 \mathrm{~mA} / \mathrm{cm}^{2}$, Pore Widened $3 \mathrm{~min} \_33$

Figure $3.22-30 \mathrm{~mA} / \mathrm{cm}^{2}$, Pore Widened $6 \mathrm{~min}, \mathrm{Co}=320 \mathrm{pF} 34$

Figure 3.23 - Pad Layout, $30 \mathrm{~mA} / \mathrm{cm}^{2}$, Pore Widened 6 min__ 34

Figure 3.24 - Distribution of Threshold Voltage as a Function of Current Density ___ 36

Figure 3.25 - Distribution of Flatband Voltage as a Function of Current Density_____ 38

Figure 3.26 - C-V Curve of a $\mathrm{Al}_{2} \mathrm{O}_{3}$ Capacitor Created by the Oxidation of AlN [25] ___ 39

Figure 3.27 - Effects of Pore Widening on Geometry___ 41

Figure 3.28 - Pore Geometry Estimation for $15 \mathrm{~mA} / \overline{\mathrm{cm}^{2} \text { Sample___ }} 43$

Figure 3.29 - Pore Geometry Estimation for $20 \mathrm{~mA} / \mathrm{cm}^{2}$ Sample___ 43

Figure 3.30 - Pore Geometry Estimation for $30 \mathrm{~mA} / \mathrm{cm}^{2}$ Sample___ 44

Figure 3.31 - Viable Dimensions of Pores of $15 \mathrm{~mA} / \mathrm{cm}^{2}$ Sample___ 45

Figure 3.32 - Viable Dimensions of Pores of $20 \mathrm{~mA} / \mathrm{cm}^{2}$ Sample___ 46

Figure 3.33 - Viable Dimensions of Pores of $30 \mathrm{~mA} / \mathrm{cm}^{2}$ Sample___ 46

Figure 4.1 - Electroplating Deposition Rate of Ni__ 52

Figure 4.2 - Sample 041701B___ 53

Figure 4.3 - Sample 041701C_53 53 
Figure 4.4 - Sample 041701D

Figure 4.5 - Sample 041701E

Figure 8.1 - Detailed Construction Plans for AEI Base 68

Figure 8.2 - Detailed Construction Plans for AEI Faceplate 69

Figure 8.3 - Detail of O-Ring Seating on Faceplate 


\subsection{Introduction}

The Nanostructures Research Group (NRG) at West Virginia University has developed a thin film porous alumina template-based nanostructure synthesis technique that has the potential for fabricating high-performance photonic and electronic devices $[1,2,10]$. The fabrication technique is based on anodization, or electrolytic oxidation, of an aluminum thin film into porous alumina that contains a periodic array of nanoscale pores. The nanostructure material is then synthesized inside these pores. When aluminum is anodized in an appropriate acidic electrolyte under controlled conditions, it oxidizes to form a hydrated aluminum oxide (alumina) containing a two dimensional hexagonal array of cylindrical pores as schematically shown in Figure 1.1.

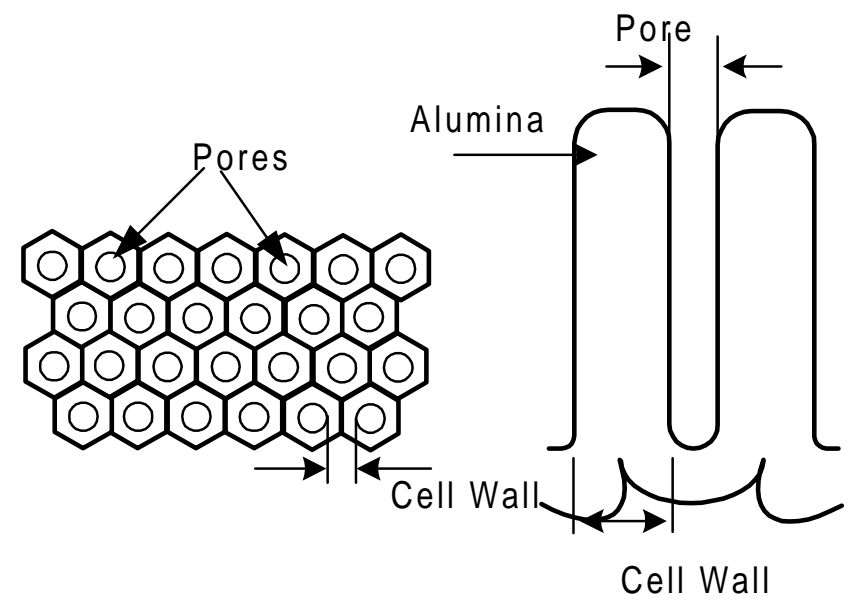

Figure 1.1 - Schematic Top and Cross-Sectional Views of Pores Formed in Anodized Alumina 
Anodization of aluminum is a well-established industrial process and is widely used for coloring and anticorrosion applications. The reaction is performed in a simple wet chemistry apparatus where the aluminum layer is polarized as the anode (positive), and a platinum electrode is used as the cathode (negative). Anodization can be performed under constant current (galvanostatic) or constant voltage (potentiostatic) conditions. Sulfuric acid and oxalic acids are typically used for the anodization of aluminum. The pore diameter and the inter-pore spacing depend on the anodization conditions such as electrolyte $\mathrm{pH}$, temperature and the anodization current density, and the aluminum microstructure features, such as grain size. The anodization parameters can be precisely controlled to form pore diameters between 4 and $100 \mathrm{~nm}$ with less than $10 \%$ variance in the pore size distribution in bulk aluminum (Figure 1.2) [24].

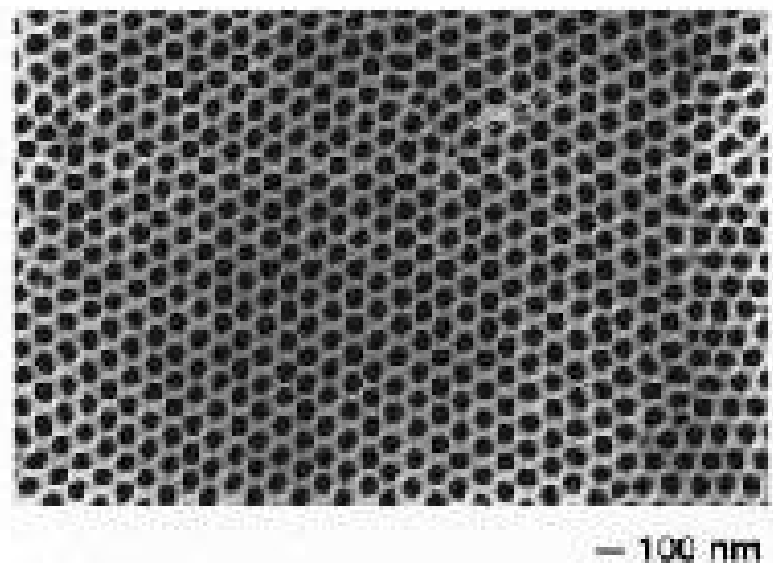

Figure 1.2 - SEM Top View of Bulk Porous Alumina Showing Highly-Ordered Pores

Pores can be up to several microns deep. Since anodized alumina is electrically insulating and transparent over a wide visible spectrum, it can be an ideal embedding material for nanoscale electronic and photonic devices. In fact, during the past fifteen 
years, porous alumina fabricated on bulk aluminum substrates has been used to synthesize various semiconductor and magnetic materials [3-6]. Nanostructures are created in the pores by electrochemical synthesis or colloidal deposition inside the pores $[3,7]$. Some of the species introduced into the bulk nanoporous alumina include: gold, nickel, iron, $\mathrm{CdS}, \mathrm{ZnS}, \mathrm{CdSe}, \mathrm{GaAs}$ and ternary semiconductor compounds $\left(\mathrm{Cd}_{\mathrm{x}} \mathrm{Zn}_{1-\mathrm{x}} \mathrm{S}\right)$. However, the use of bulk alumina precludes most photonic and electronic device applications due to the opaque nature of the unconverted aluminum substrate, and the inability to integrate the nanostructure arrays with other devices. To overcome this barrier, the NRG and the University of Notre Dame extended this fabrication technique by using an aluminum thin film deposited on a silicon substrate as the basis for template fabrication, and have since extended it to other substrates including glass and ITO coated glass [2]. NRG and Notre Dame are currently working on the implementation of a variety of photonic and electronic devices based on this thin film template based synthesis technique.

The overall objective of this thesis is to advance the preceding fabrication technique towards the realization of high-performance nanoscale devices. The specific contributions of this thesis are: (i) the development of an improved anodization apparatus that significantly increases wafer throughput and safety, (ii) the development of electrical characterization tools for the alumina templates, and (iii) process development for the synthesis of nickel nanostructures. The remainder of the thesis is organized as follows. Chapter 2 discusses the evolution of several versions of anodization equipment that are consistently used throughout the remainder of the research. In Chapter 3, 
electrical characterization techniques, which provide information regarding the template and template-substrate interface, are explained. In Chapter 4, a method for creating nickel nanostructures using electrochemical deposition is described. Finally, Chapter 5 presents a summary and conclusions of this thesis. 


\subsection{Development of an Improved Anodization}

\section{Apparatus}

Anodization is the primary process step in the template-based nanostructure fabrication technique. Anodization is also an important process step for the formation of porous silicon, which has been a topic of significant interest because of its ability to emit visible light [9-11]. This chapter describes the contributions of this thesis towards the development of an improved anodization apparatus and its impact on the template-based nanofabrication technology research.

\subsection{Earlier Anodization Apparatus}

Although the anodization process has been around for many decades, the anodization apparatus and procedure have remained relatively unchanged. Anodization is typically performed in an apparatus similar to the one shown in Figure 2.1, which is the first improved version developed by the NRG. This is an improvement over typical cells, where the sidewalls are vertical and the wafer is mounted at the bottom or sidewall of the cell. The slanted mounting area on the sidewall was a design improvement to increase heat removal by preventing eddy currents near the wafer surface. The bottom of the cell has a removable cover, where the substrate is placed on an O-ring. When the cover is fixed securely to the bottom of the tank, the O-ring forms a seal that prevents leakage of the electrolyte from the cell. Electrical contact to the substrate is achieved by a metallic spring or strip on the metallized back of the substrate. Anodization is performed using a 
few simple steps. First, the substrate is placed on the O-ring and the cover is replaced.

Second, the electrolytic solution is transferred to the container. Next, anodization is performed by inducing a constant current between the substrate and the platinum cathode immersed in the electrolyte. The electrolyte is circulated during anodization to remove the heat generated by the electrochemical reactions. After the anodization is completed, the solution is transferred out of the container, and the cover is removed to retrieve the anodized substrate, which is then rinsed and dried.

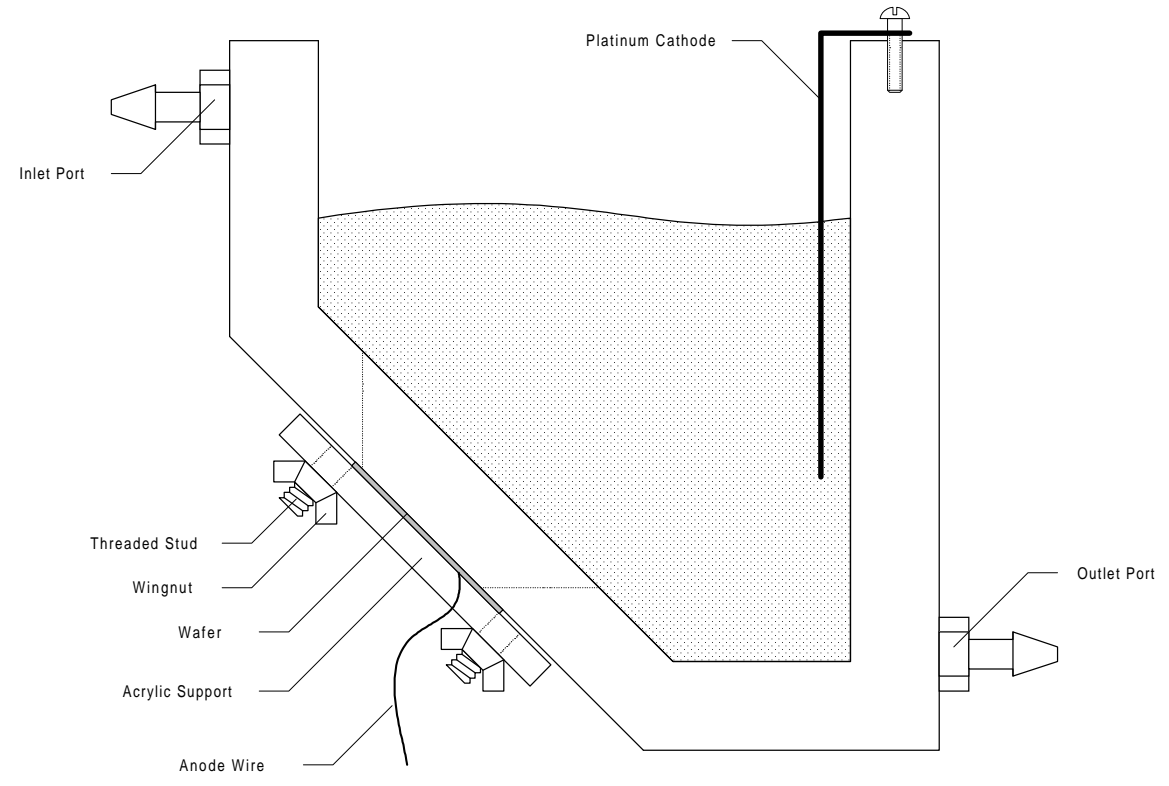

Figure 2.1 - First Anodization Apparatus Developed by NRG 
Although the anodization apparatus described above is fairly straightforward to implement, it has many limitations as listed below.

(i) The procedure is slow due to the time required to safely mount the sample and transfer the electrolyte before and after anodization.

(ii) The hazardous electrolytic solution has to be transferred before and after each anodization; this excessive acid handling is not only wasteful, but also poses a safety concern.

(iii) The equipment is not very versatile in terms of wafer size and shape, which is determined by the O-ring and the cover. Thus, to anodize wafers of different sizes, different anodization cells are required.

(iv) The equipment and the process are not suitable for economic volume production.

In order to overcome these drawbacks, two different versions of the apparatus were developed as a part of this thesis [14]. The improved apparati are efficient, safe, flexible regarding wafer size, and are appropriate for commercial volume production. 


\subsection{Vacuum Immersion Apparatus}

The first improvement on the anodization process developed as part of this thesis is the vacuum immersion apparatus shown in Figure 2.2. The apparatus consists of four main components: an aluminum structural frame, an aluminum Y-direction carriage, a Teflon

Z-direction immersion assembly, and a user control panel. Currently, wafers are fed into - and taken from - the process manually. However, this system is fully compatible with a belt-driven wafer delivery and extradition system, allowing for integration into a fully automated semiconductor manufacturing facility. An important difference between this apparatus and the traditional one described above is the way the substrate is mounted on the Teflon immersion assembly. In this apparatus, the substrate is not used as a seal for the hazardous electrolytic solution; it is secured to the Teflon sample holder by means of a small vacuum port surrounding the gold spring contact, as shown in Figure 2.3. Thus, O-rings are not necessary in this setup and substrates of any size and shape can be used. 


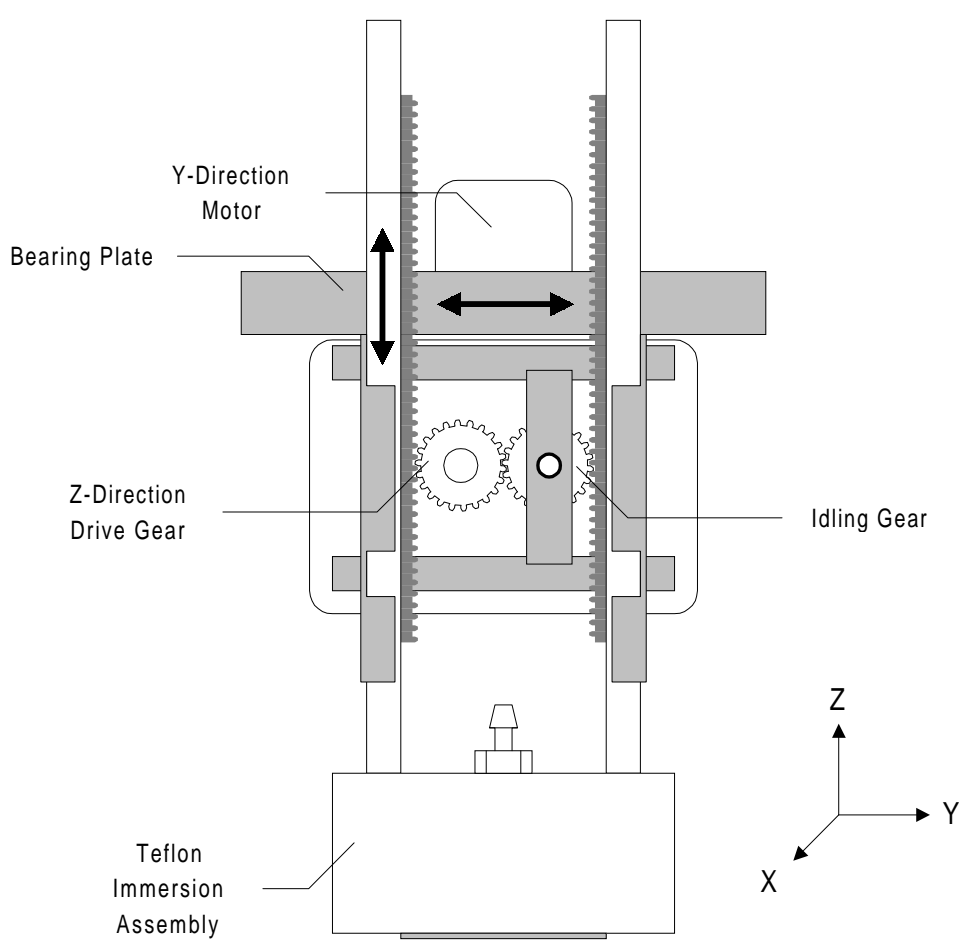

Figure 2.2 - Vacuum Immersion Apparatus

The vacuum immersion apparatus is based upon a Y-Z robotic manipulator that moves the silicon wafer through the various stages of the anodization process (Figure 2.2). Horizontal motion is realized through a unipolar stepper motor fitted with a 32-pitch gear. This gear mates with a 32-pitch rack secured to the top of the apparatus framework. The four phases of the motor are driven by the PIC16F84 microcontroller and buffered through power transistors. By varying the order and rates of phase firing, the overall horizontal motion of the carriage assembly may be controlled. Friction is reduced through the use of Nylon bearing strips placed in parallel with the toothed rack. No feedback for horizontal motion is required because travel throughout the processing cycle of each wafer is limited to the negative Y direction. Vertical motion is realized through a 12 VDC motor also fitted with a 32-pitch gear. This gear mates with an identical idling 
gear secured to the carriage. These two gears mate with vertically mounted 32 pitch racks that are fastened to Teflon rods, which in turn support the solid Teflon immersion assembly. The motor is driven using an integrated circuit that is responsible for speed, direction and braking throughout vertical motion. Speed feedback is realized by an infrared transmitter-detector pair, mounted across the teeth in the rack. By taking this information into account, the PIC processor may calculate the proper depth to immerse a wafer, given the depth of the acid bath.

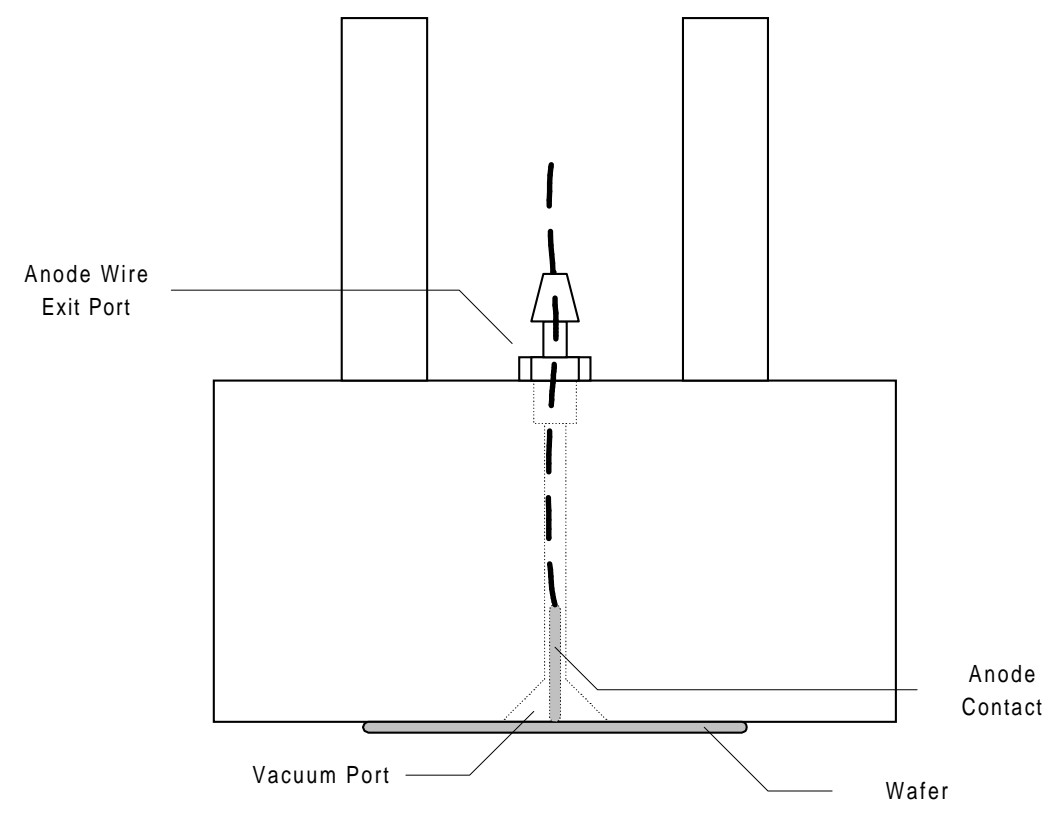

Figure 2.3 - Vacuum Immersion Assembly

The operator interface is realized through a control panel located remotely from the anodization system. This remote interface provides a high degree of safety not currently available in other anodization systems. The entire mechanical processing system may be enclosed in a fume hood or behind splashguards to protect the user from the process 
chemicals. Only a single control cable is required to tether the operator to the reaction equipment. The anodization process may be controlled in either the Manual or Automatic mode, by properly setting the Manual / Automatic switch on the control panel. This allows a precise human interface for delicate experimental work, while maintaining full automation capabilities for large-scale production runs. In Manual mode, the operator is fully responsible for all process motion and timing. Horizontal and vertical movements are controlled by large toggle switches on the control panel. In this mode, the operator may intervene in an erroneous cycle, or perform experiments that do not follow the traditional anodization process. In Automatic mode, the user programs the time constraint for the anodization and rinse portions of the cycle through a numeric keypad on the control panel. Time constraints are entered for both the anodization and rinse cycles. The user may also enter the number of substrates that the system should process under these specifications. Once the operator confirms these settings, the system automatically performs the anodization cycle(s) according to the input specifications.

\subsection{Aperture Exposure Immersion Apparatus}

Although the Vacuum Immersion system outlined in section 2.2 provided several considerable advantages over the Standard Anodization Technique of 2.1, it was replaced by the more elegant process of Aperture Exposure Immersion (AEI), also developed as a part of this thesis. AEI provides a means of anodizing a select region of the sample, as opposed to its entire surface. This style of anodization allows exposure of several areas on a single wafer to varying electrolytic reactions, at a very high throughput. 
$\mathrm{AEI}$ is similar to the previous apparatus in that the sample is vertically immersed into the electrolyte bath. However, in AEI, the sample is held in place not by vacuum, but by an aperture assembly constructed of Teflon (Figure 2.4.) This mask protects the bulk of the sample while template formation occurs in an insolated area.
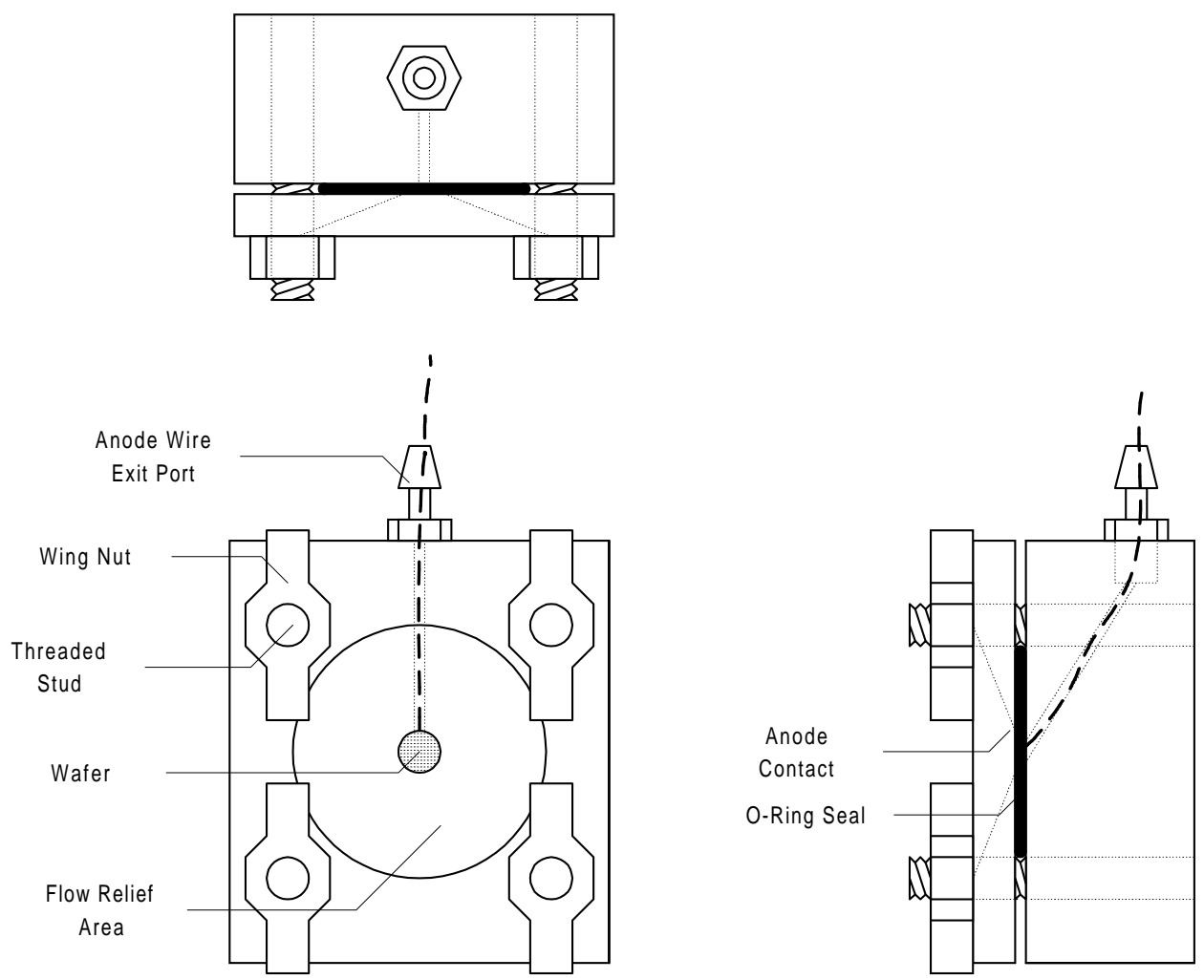

Figure 2.4 - Aperture Exposure Immersion Assembly

A sample wafer is loaded by placing it on a $3.8 \mathrm{~mm}$ thick $\mathrm{Cu}$ anode contact table located inside a Teflon O-ring. The height of this table may be raised or lowered for substrates of varying thickness by adjusting the three screws that it rests upon. Next, a Teflon mask is placed on top of the sample, ensuring that the appropriate area is exposed through the 
aperture. Another Teflon O-ring provides a liquid-tight seal that also holds the wafer sample in place. Four hinged arms that fold up from two opposite sides then secure this mask. On each arm is a threaded Teflon wing nut that is tightened until the mask and sample are held firmly in place.

On the first AEI constructed, a shallow relief was carved around the aperture to reduce the effects of shadowing and to increase the electrolyte circulation. It was later found that this relief compromises the strength of the mask and allows it to flex quite easily. In several cases, the electrolytic solution leaked into the chamber and caused corrosion. To correct this problem, a second mask was created using a vertical hole with no relief area. Experimentation has proven that aperture shape has little effect on shadowing.

Once the sample is firmly fixed in the AEI, the entire assembly is lowered into a 2 liter Teflon beaker containing the electrolytic solution. Connections are made as shown in Figure 2.5.

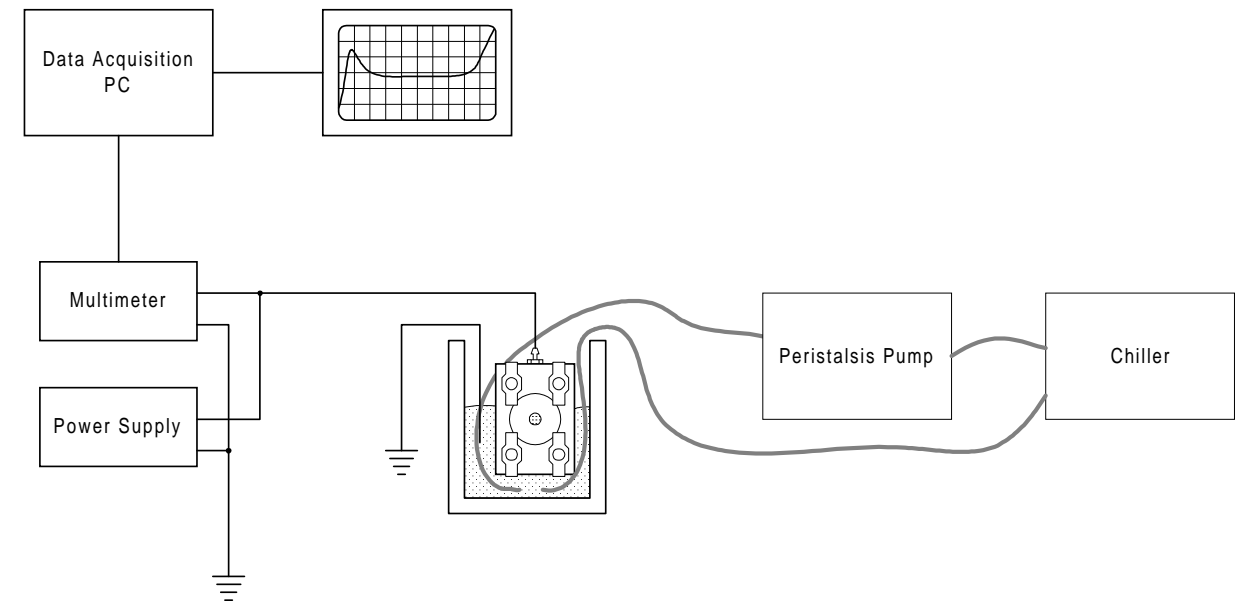

Figure 2.5 - Anodization Setup 


\subsection{Anodization Process}

Regardless of the apparatus used, the actual anodization procedure remains essentially the same. The back of the sample to be anodized is sputtered with a layer of Al alloy at least $100 \mathrm{~nm}$ thick to provide a back electrical contact. This contact constitutes the anode of the electrolytic reaction. To anodize templates on insulating substrates, a small piece of conductive foil is wrapped around the edge of the sample so that contact is made between the top of the sample and the copper plate below. A Pt wire immersed in the electrolytic solution opposite the material to be anodized provides the cathode. It is important to ensure that this wire is as far from the sample as possible to produce uniform current fields and to reduce the effects of fringing. A distance of $5 \mathrm{~cm}$ or more is recommended.

Using the AEI technique, the sample is placed on the $3.8 \mathrm{~mm}$ thick copper plate electrode, creating an electrical contact. A Teflon-insulated 22AWG Al wire provides connection to this plate. The sample is fixed in place by the Teflon aperture mask and lowered into a 2 liter Pyrex beaker containing the electrolytic solution. For $\mathrm{Al}_{2} \mathrm{O}_{3}$ templates, $200 \mathrm{ml}$ of $\mathrm{H}_{2} \mathrm{SO}_{4}$ and $800 \mathrm{ml}$ of $\mathrm{H}_{2} \mathrm{O}$ are mixed to create this electrolyte. The electrolyte is chilled to $1^{\circ} \mathrm{C}$ and circulated for the duration of the process.

Once the anode and cathode contacts are connected to the power supply, a constant current is passed through the solution and sample. Current densities in the range of 5 to $70 \mathrm{~mA} / \mathrm{cm}^{2}$ have been successfully used to create $\mathrm{Al}_{2} \mathrm{O}_{3}$ templates. The voltage is 
recorded as a function of time by a multimeter that interfaces to a PC. Once anodization is complete, the sample is removed and rinsed in deionized $\mathrm{H}_{2} \mathrm{O}$, then dried with $\mathrm{N}_{2}$.

It has been shown [21] that pore formation geometries in the alumina layer are proportional to the anodization voltage. Pore spacing (center to center of nearest neighbors) obeys a constant of $2.5 \mathrm{~nm} / \mathrm{V}$, and pore diameters are governed by a constant of $1.29 \mathrm{~nm} / \mathrm{V}$. 


\subsection{Capacitance Voltage Characterization of Templates}

Capacitance-voltage measurement (CV) is a widely accepted means of testing metal oxide semiconductor (MOS) capacitor samples and determining device parameters such as carrier density, Fermi level, flatband voltage and threshold voltage. These values not only serve as the basis for other calculations, but also provide valuable data regarding device performance. Since anodized alumina is an insulator, $\mathrm{CV}$ characterization could potentially be used to characterize the templates as well as the template/silicon interface. Towards this goal, this thesis investigated MOS capacitors formed by aluminum/porousalumina/silicon structures, as shown in Figure 3.1.

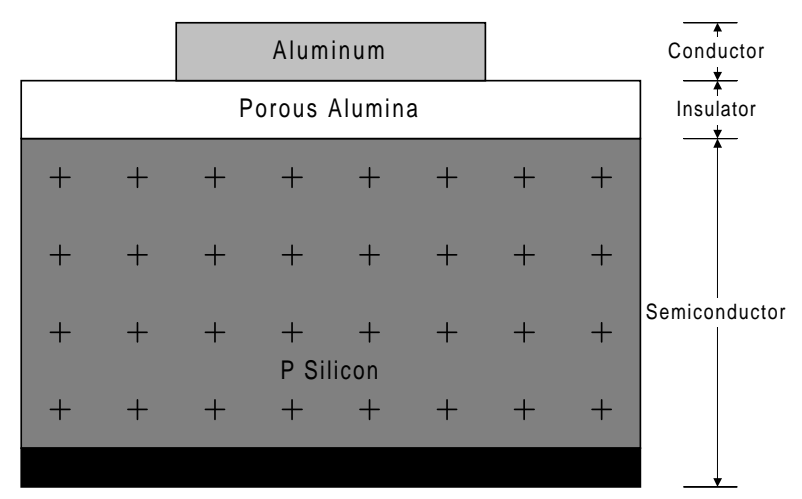

Figure 3.1 - Cross Section of a MOS Capacitor Formed by a Porous Alumina Insulator 


\subsection{Theoretical Background}

The capacitance of an MOS structure depends on whether the semiconductor is in accumulation, depletion, or inversion, and thus is a function of the bias voltage. These regions (for a P-type wafer) are shown in Figure 3.2. CV characteristics are obtained by measuring the capacitance of a device at different bias voltages using a small superimposed AC signal.

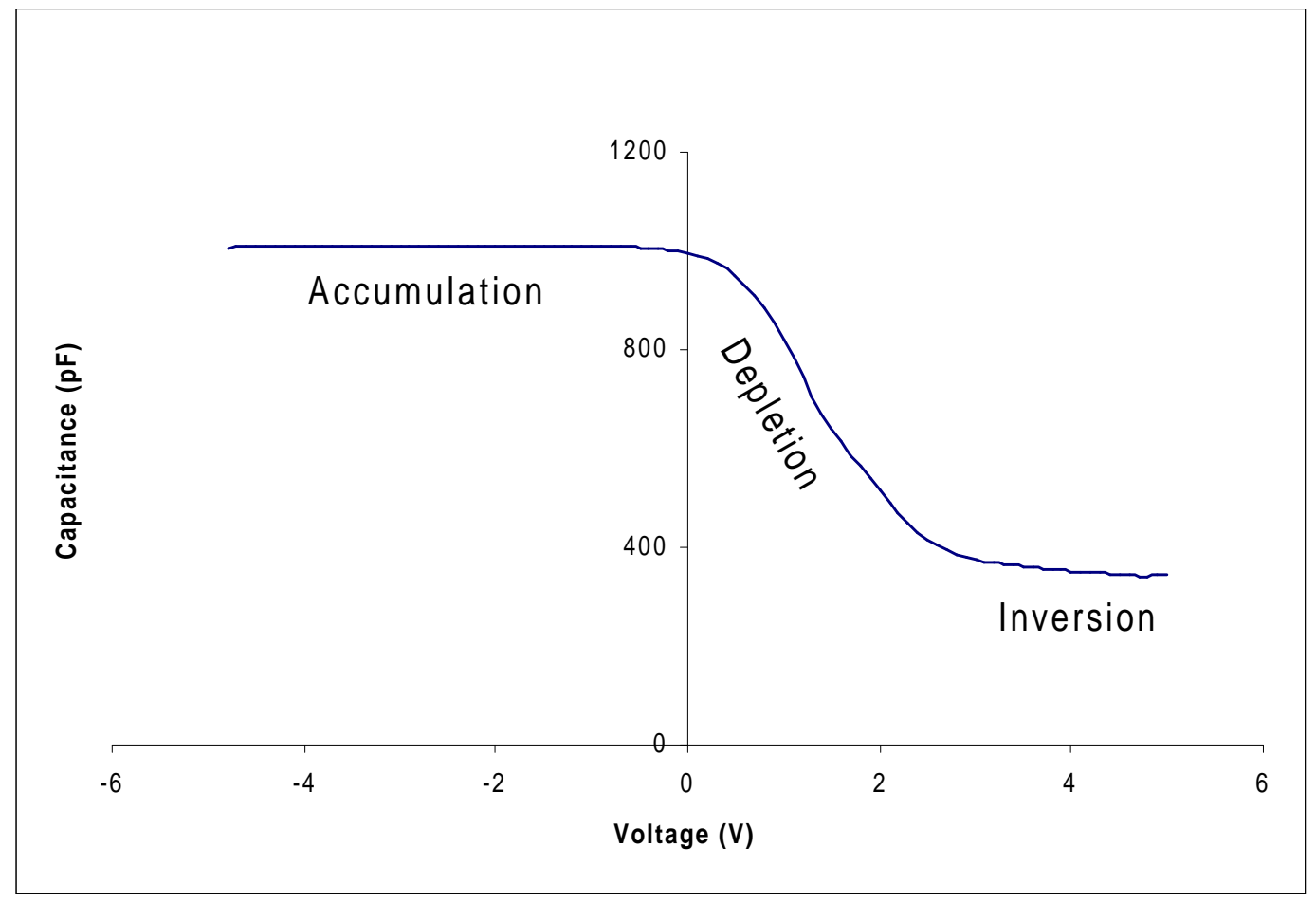

Figure 3.2 - Typical Capacitance Voltage Scan of a P-type MOS device 
Accumulation occurs when the majority carriers are attracted to the oxide-semiconductor interface by an external DC bias, which for the P-type wafers used in this research, takes place with a negative bias. During accumulation, device capacitance is independent of the bias voltage. The highly doped silicon is a good conductor, therefore the addition of majority carriers has little or no effect on the capacitance. In this region, the capacitance $\left(C_{o}\right)$ may be described by:

$$
C_{o}=\frac{\mathcal{E}_{o x} \cdot A}{t_{o x}}
$$

where $t_{o x}$ represents the oxide thickness, $\varepsilon_{o x}$ is the oxide permittivity, and $A$ is the area of the top contact. During accumulation, the device has a capacitance that is approximately equal to the capacitance under no bias.

In the depletion region, small forward-bias voltages begin to repel holes from the interface. This repulsion creates a depletion layer in the semiconductor, just below the oxide layer. As the magnitude of this bias grows, so does the thickness of the depletion layer. This activity makes the capacitor respond as if its conducting plates were being pulled apart, thereby resulting in a smaller device capacitance. The capacitance continues to diminish as a function of bias, until a threshold voltage is reached, where inversion occurs. 
Once the gate voltage reaches the threshold voltage, the device enters the inversion region, where a thin layer of negative charge is collected at the oxide/semiconductor interface. The capacitance under this condition depends upon the frequency of measurement. At low frequencies $(<100 \mathrm{~Hz})$ thermally generated minority carriers (electrons in this case) approach the interface. As the forward voltage is increased, more electrons are generated, and an equilibrium condition is reached. At this point, device capacitance is once again independent of the applied voltage, and approximately equal to $\mathrm{C}_{\mathrm{ox}}$. At higher frequencies $(>100 \mathrm{~Hz})$ the presence of majority carriers (holes)

overshadows the small numbers of electrons being thermally generated. Since the electrons cannot respond to the high frequency signal, their effects are negligible. In this case, device capacitance is lowered, as determined by the sum of the thickness of the oxide and the depletion layers attained at the onset of inversion.

The energy band diagrams of these regions are given in Figure 3.3 below.

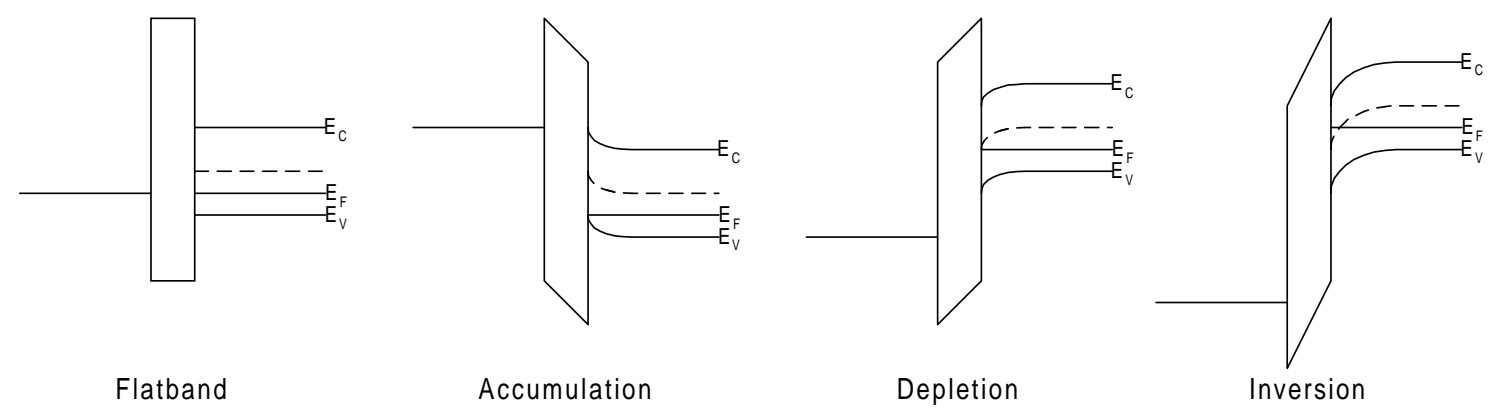

Figure 3.3 - Energy Band Diagrams of a P-MOS Capacitor 


\subsection{Device Fabrication}

A number of aluminum/porous alumina/P-Si MOS capacitors were fabricated using the following technique. P-type silicon substrates were first summa-cleaned, then immersed in a $1 \% \mathrm{HF}$ bath, rinsed, and dried with $\mathrm{N}_{2}$. Then, a $100 \mathrm{~nm}$ layer of $\mathrm{Al}$ was sputter deposited on the back of the wafer, followed by annealing at $450^{\circ} \mathrm{C}$ for 30 minutes. Next, a $100 \mathrm{~nm}$ layer of $\mathrm{Al}$ was deposited on the top of the wafer, which was then annealed at $400^{\circ} \mathrm{C}$ for 30 minutes to ensure good adhesion. The wafers were then anodized in $20 \%$ sulfuric acid at current densities of 15,20 and $30 \mathrm{~mA} / \mathrm{cm}^{2}$. Some of these wafers were then pore widened in $5 \%$ phosphoric acid for either 3 or 6 minute durations. The purpose of pore widening is to remove any remaining barrier layer (alumina) at the alumina/silicon interface, as well as to remove impurity ions remaining from the anodization process. Finally, a number of $\mathrm{Al}$ contacts, each $1.59 \mathrm{~mm}$ in diameter, were sputtered through a shadow mask on top of the template to create the capacitors (Figure 3.4). A schematic cross section is provided in Figure 3.5. Table 3.1 lists the various samples that were used in this experiment.

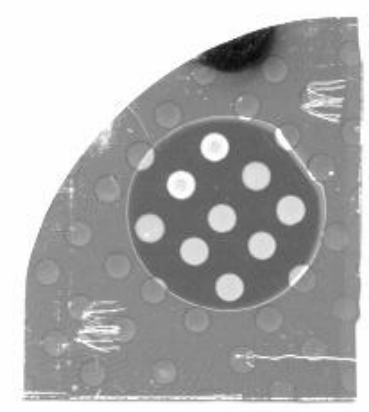

Figure 3.4 - MOS Capacitors with Porous Oxide Layer 


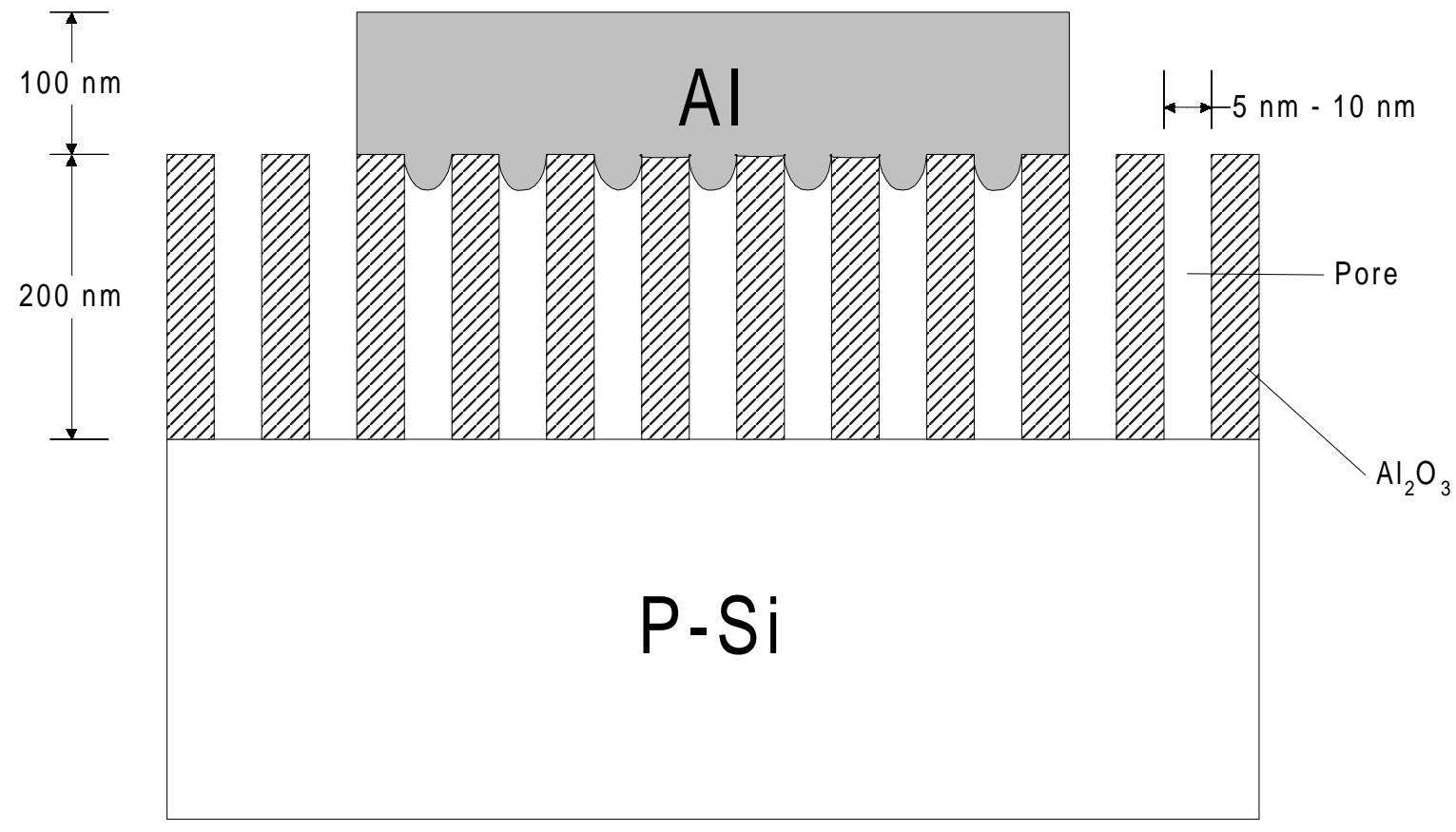

Figure 3.5 - Schematic Representation of a Single MOS Capacitor

\begin{tabular}{|c|c|c|c|}
\hline $\begin{array}{c}\text { Anodization } \\
\text { Current Density }\end{array}$ & $\begin{array}{c}\text { Not Pore Widened } \\
\text { (number of wafers) }\end{array}$ & $\begin{array}{c}\text { Pore Widened 3 min } \\
\text { (number of wafers) }\end{array}$ & $\begin{array}{c}\text { Pore Widened 6 min } \\
\text { (number of wafers) }\end{array}$ \\
\hline $15 \mathrm{~mA} / \mathrm{cm}^{2}$ & 2 & 1 & 1 \\
\hline $20 \mathrm{~mA} / \mathrm{cm}^{2}$ & 2 & 1 & 1 \\
\hline $30 \mathrm{~mA} / \mathrm{cm}^{2}$ & 2 & 1 & 1 \\
\hline
\end{tabular}

Table 3.1 - List of Samples Used for CV Measurement 


\subsection{Measurements}

CV and IV measurements were performed on the samples by using an HP 4275 LCR meter and a probe station. Before any measurements were taken, the LCR meter was turned on and allowed to stabilize for at least 2 hours. Each wafer to be characterized was placed on a probe station and each of the individual $\mathrm{Al}$ pads was contacted using a needle probe, as shown in Figure 3.6. Once the sample was connected to the instrumentation cables, the microscope light was turned off, and the cover to the probe station was closed. A heavy black cloth was placed over the station to block ambient light and guard against any photocurrent effects.

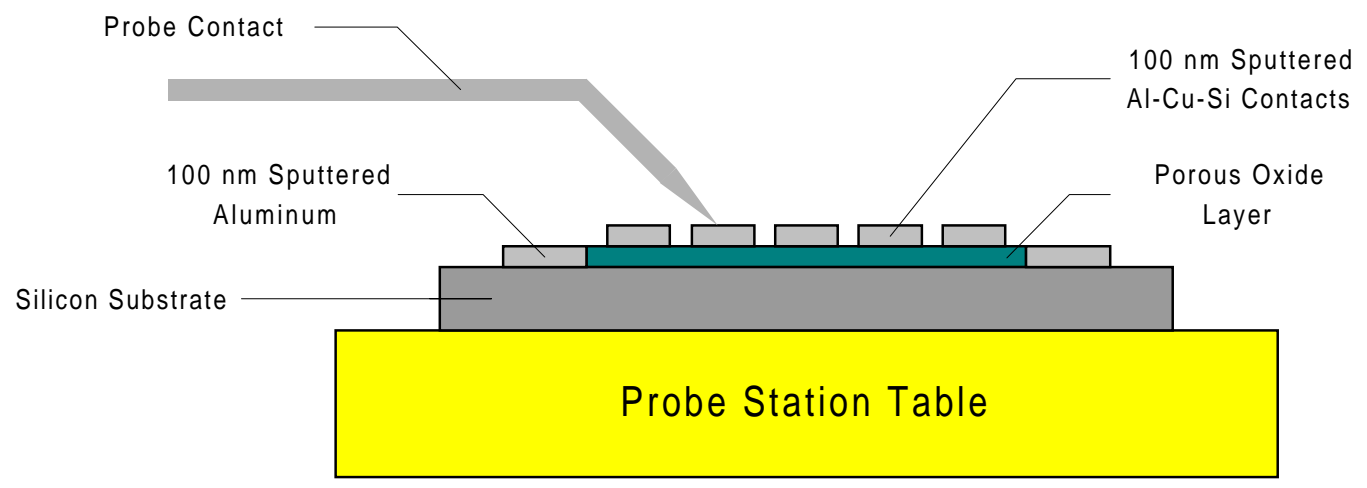

Figure 3.6 - Probe Station Setup 
Capacitance measurements were performed at a frequency of 1.0 MHz. The bias voltage was varied from -15 VDC to +15 VDC, using the HP 4140A DC voltage source, controlled by Lab View software. For the pore widened samples, a DC bias range of -5 VDC to +5 VDC was used to avoid excessive leakage currents. At each bias point, the capacitance was recorded by a PC connected to the HP LCR meter.

\subsection{Results and Analysis}

First, current-voltage (IV) measurements were performed on each capacitor sample to determine the range of bias voltages to be used for CV measurements. Typical currentvoltage results for pore-widened and non-widened samples are shown in Figures 3.7 and 3.8 , respectively. On each wafer, the 5 devices with the lowest leakage currents were selected for $\mathrm{CV}$ measurements. For each of these selected devices, three CV scans were taken. 


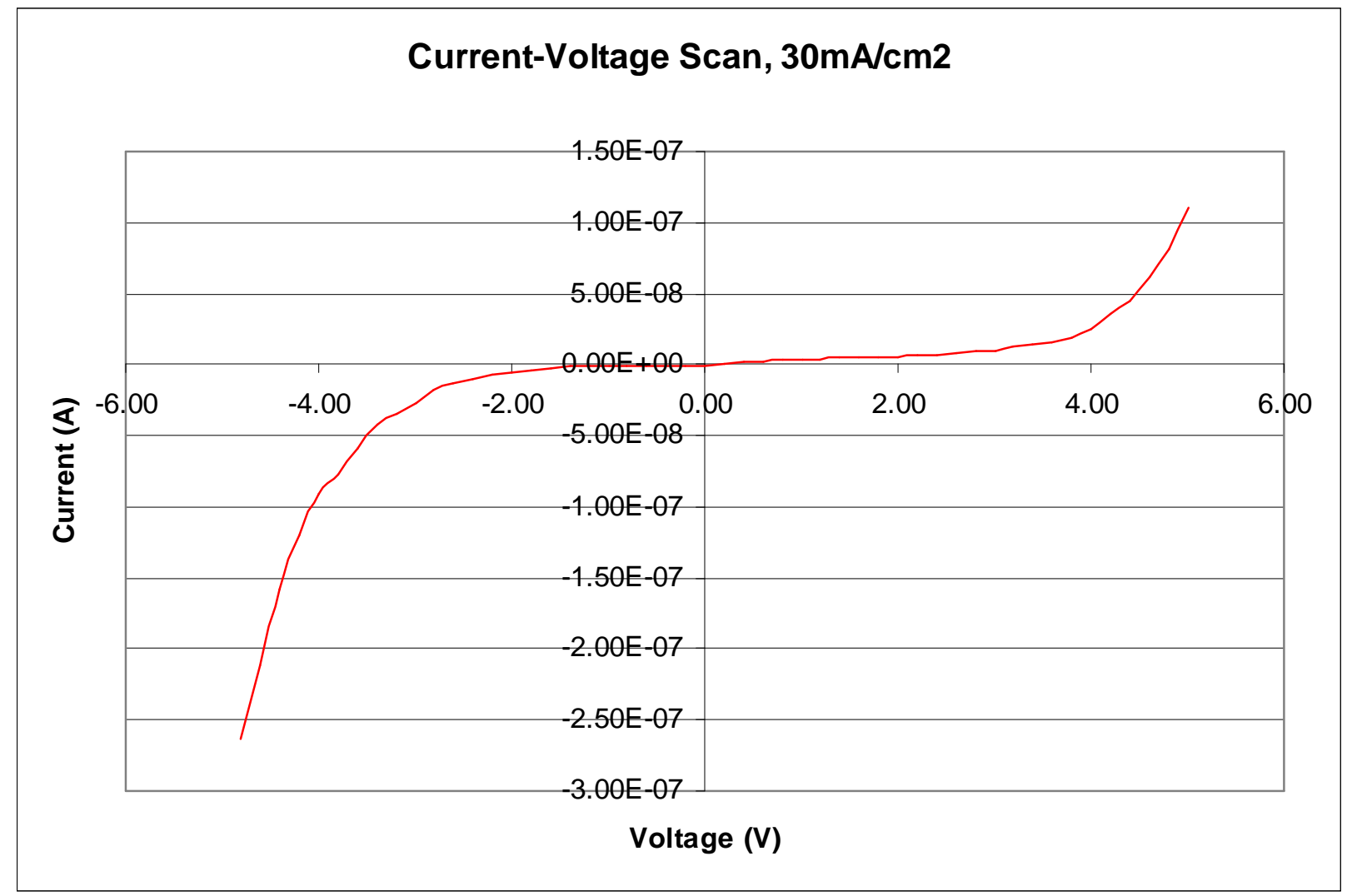

Figure 3.7 - Typical Current-Voltage Data for Pore-Widened Samples 


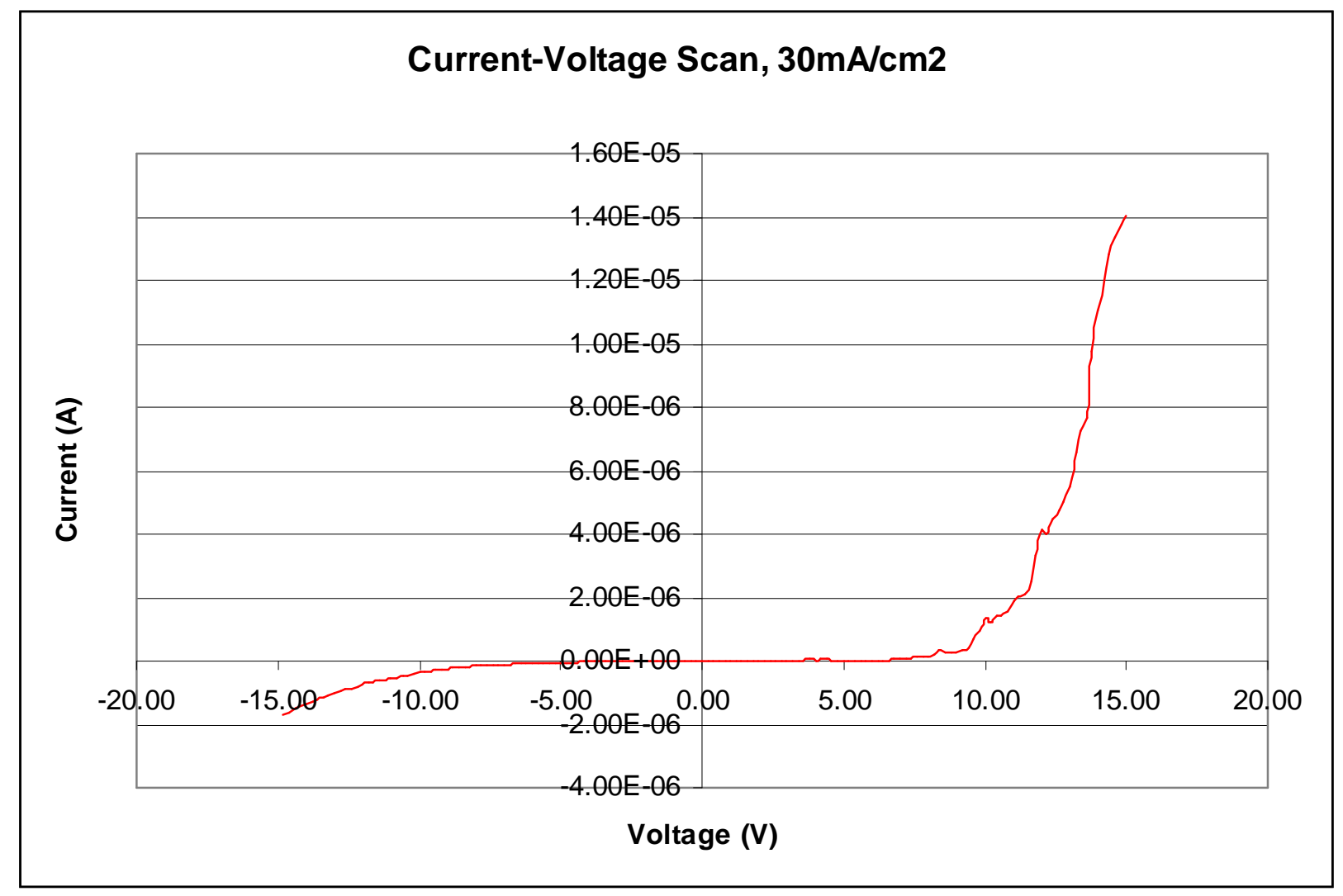

Figure 3.8 - Typical Current-Voltage Data for Samples With No Pore Widening

To correct for noise, these three measurements were averaged to provide a characteristic profile for a single device. This process was repeated across the 5 selected devices on each of the 12 samples, for a total of 180 measurements. The results of CV measurements on the different samples are shown in Figures 3.9 through 3.23. A Matlab program was written to analyze the resulting data and calculate device parameters such as theoretical carrier density, threshold voltage, and flatband voltage. 


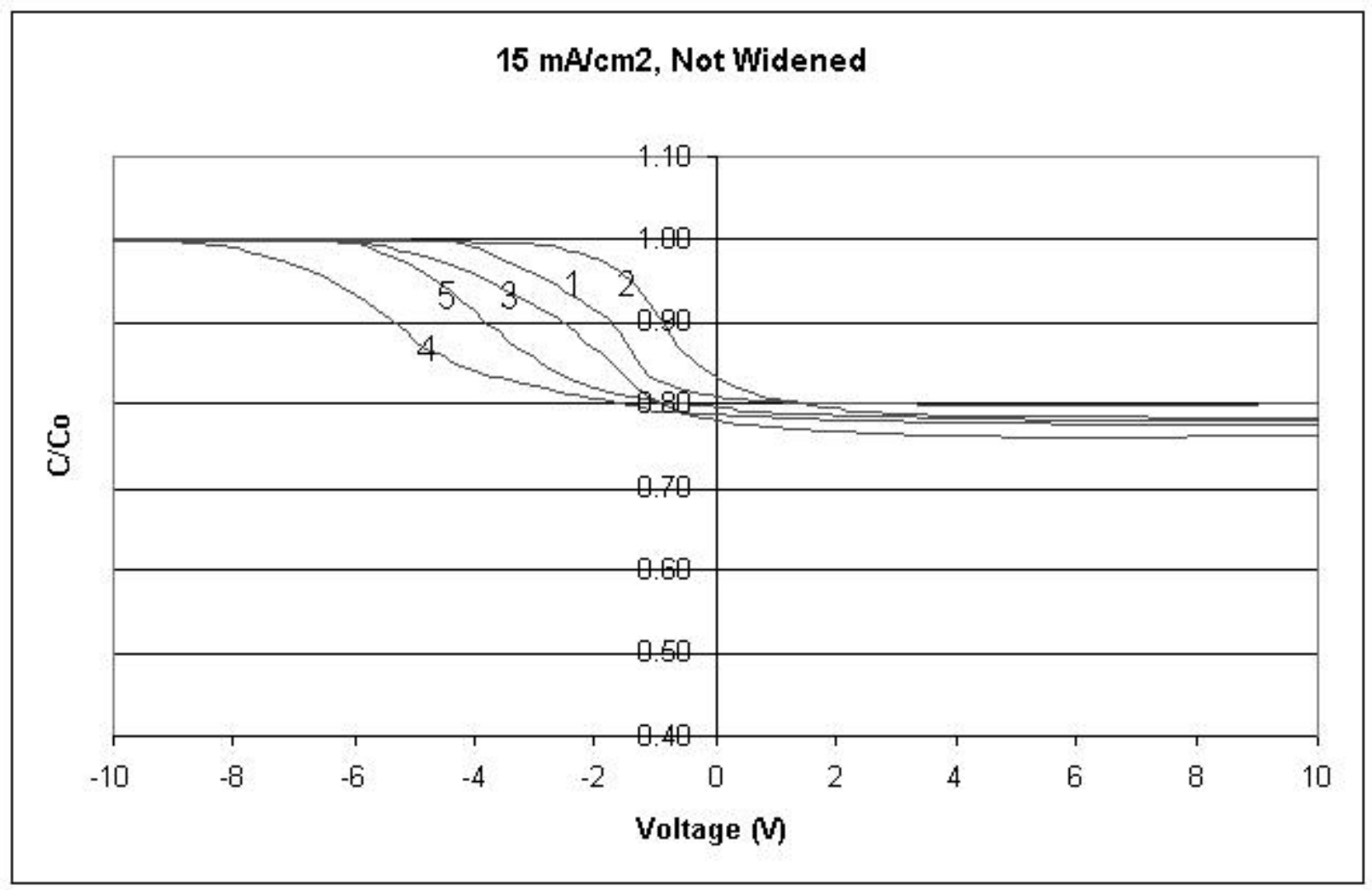

Figure 3.9 - $15 \mathrm{~mA} / \mathrm{cm}^{2}$, Not Pore Widened, Co $=174 \mathrm{pF}$ 


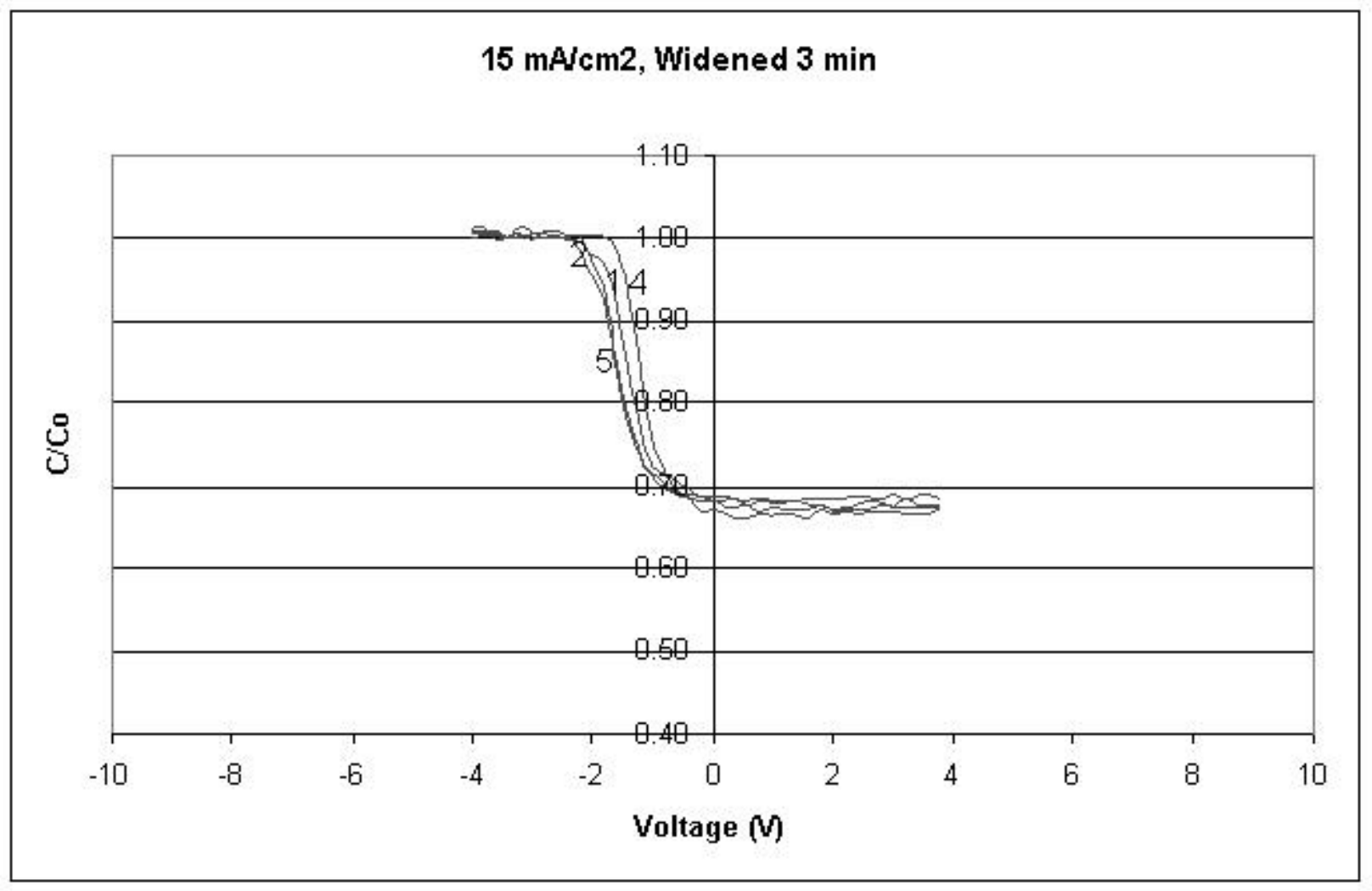

Figure $3.10-15 \mathrm{~mA} / \mathrm{cm}^{2}$, Pore Widened $3 \mathrm{~min}, \mathrm{Co}=300 \mathrm{pF}$

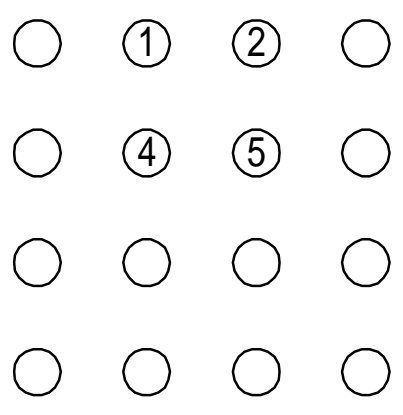

Figure 3.11 - Pad Layout, $15 \mathrm{~mA} / \mathrm{cm}^{2}$, Pore Widened $3 \mathrm{~min}$ 


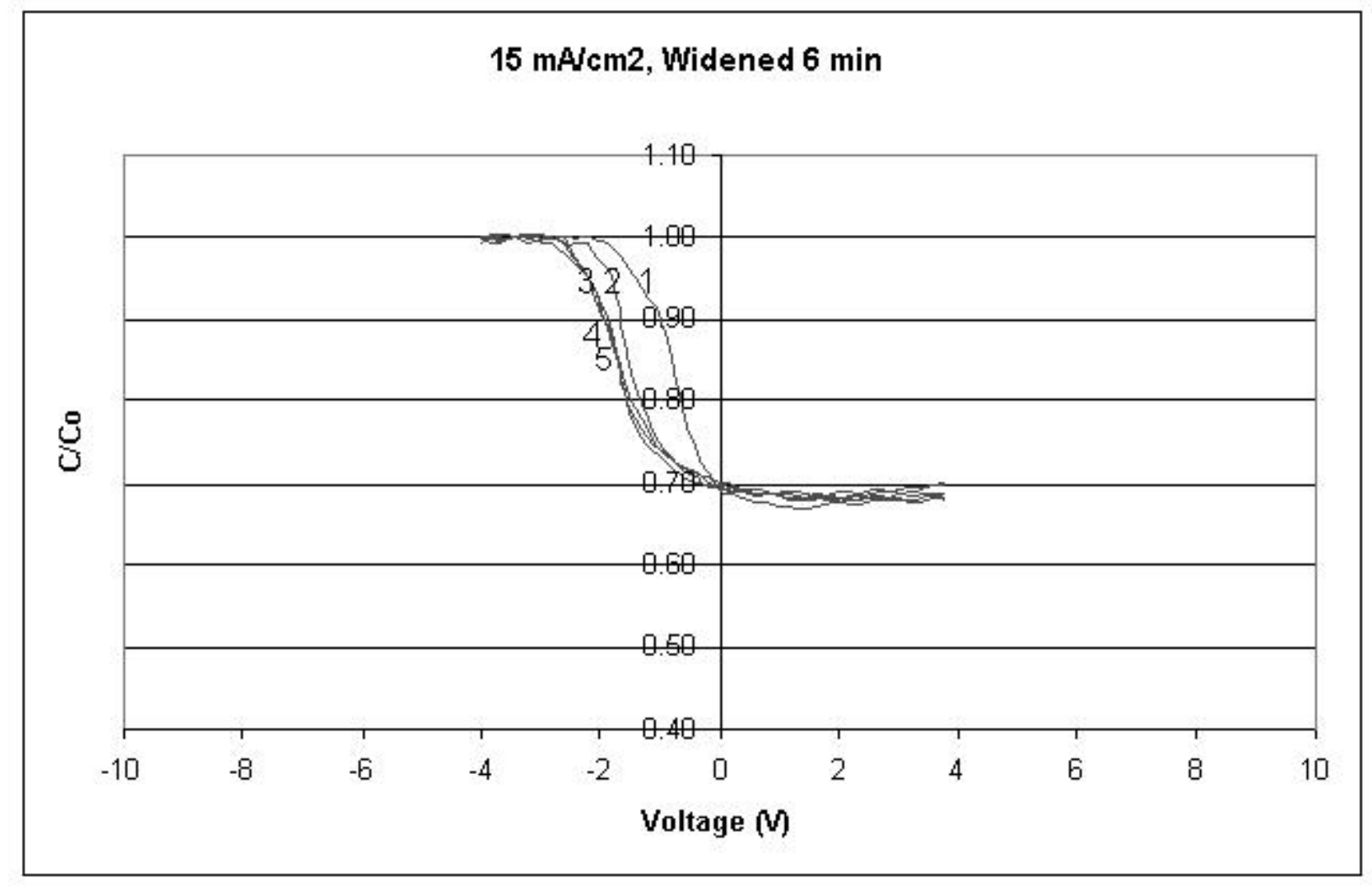

Figure 3.12 $-15 \mathrm{~mA} / \mathrm{cm}^{2}$, Pore Widened $6 \mathrm{~min}, \mathrm{Co}=300 \mathrm{pF}$

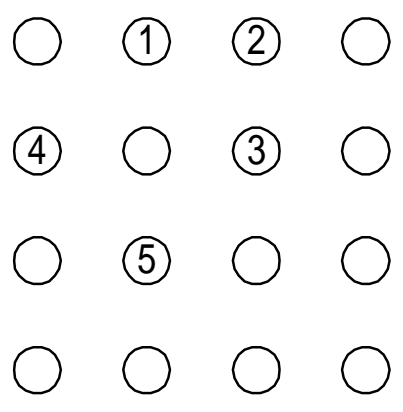

Figure 3.13 - Pad Layout, $15 \mathrm{~mA} / \mathrm{cm}^{2}$, Pore Widened $6 \mathrm{~min}$ 


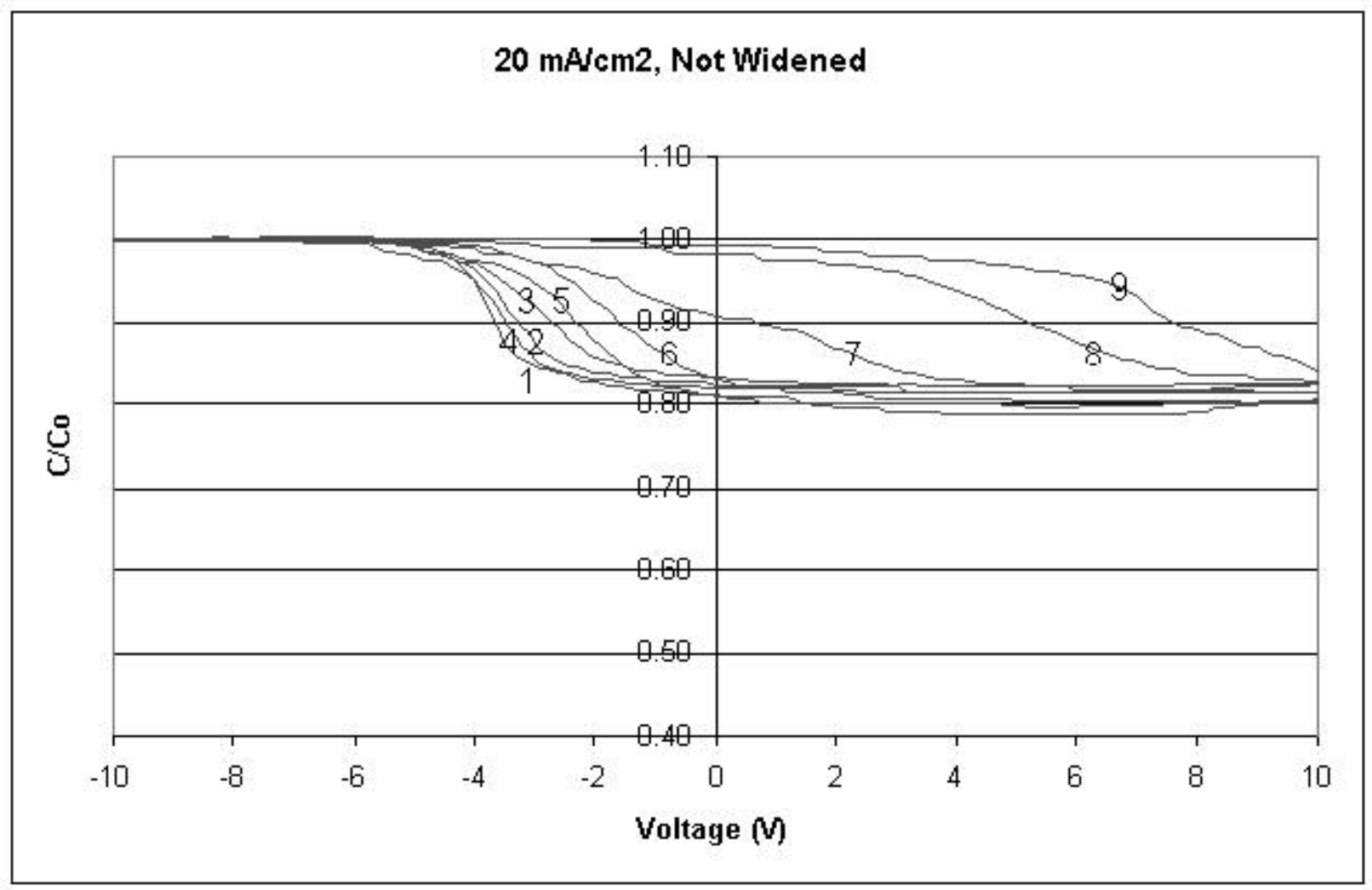

Figure 3.14 - $20 \mathrm{~mA} / \mathrm{cm}^{2}$, Not Pore Widened, Co $=143 \mathrm{pF}$ 


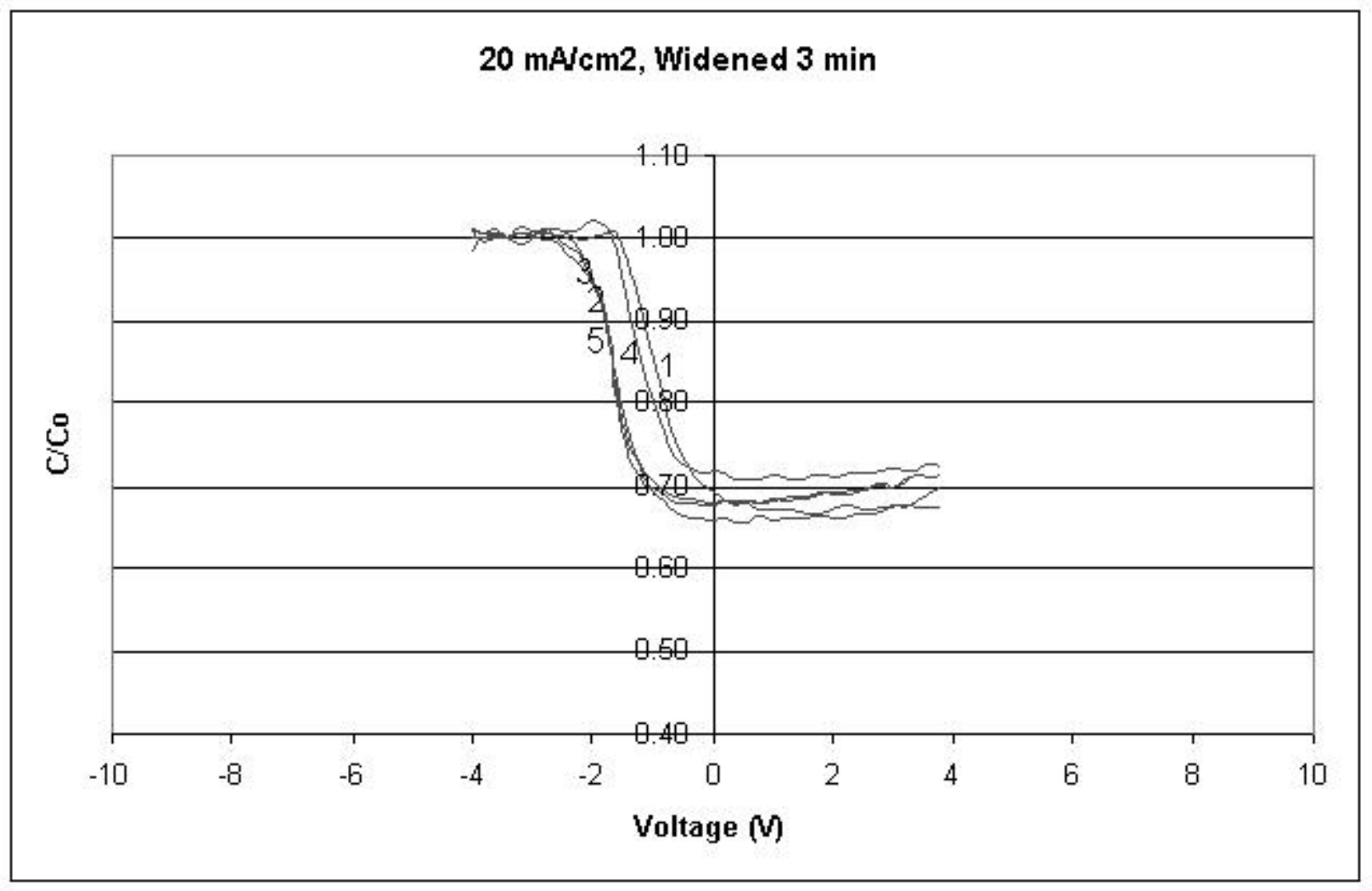

Figure $3.15-20 \mathrm{~mA} / \mathrm{cm}^{2}$, Pore Widened $3 \mathrm{~min}, \mathrm{Co}=260 \mathrm{pF}$

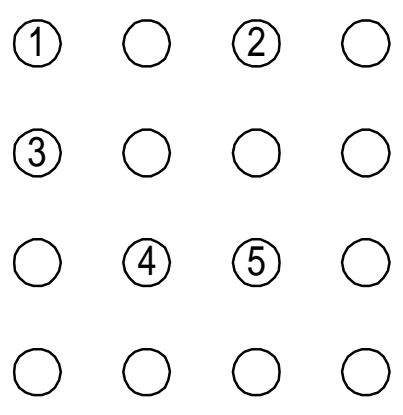

Figure 3.16 - Pad Layout, $20 \mathrm{~mA} / \mathrm{cm}^{2}$, Pore Widened $3 \mathrm{~min}$ 


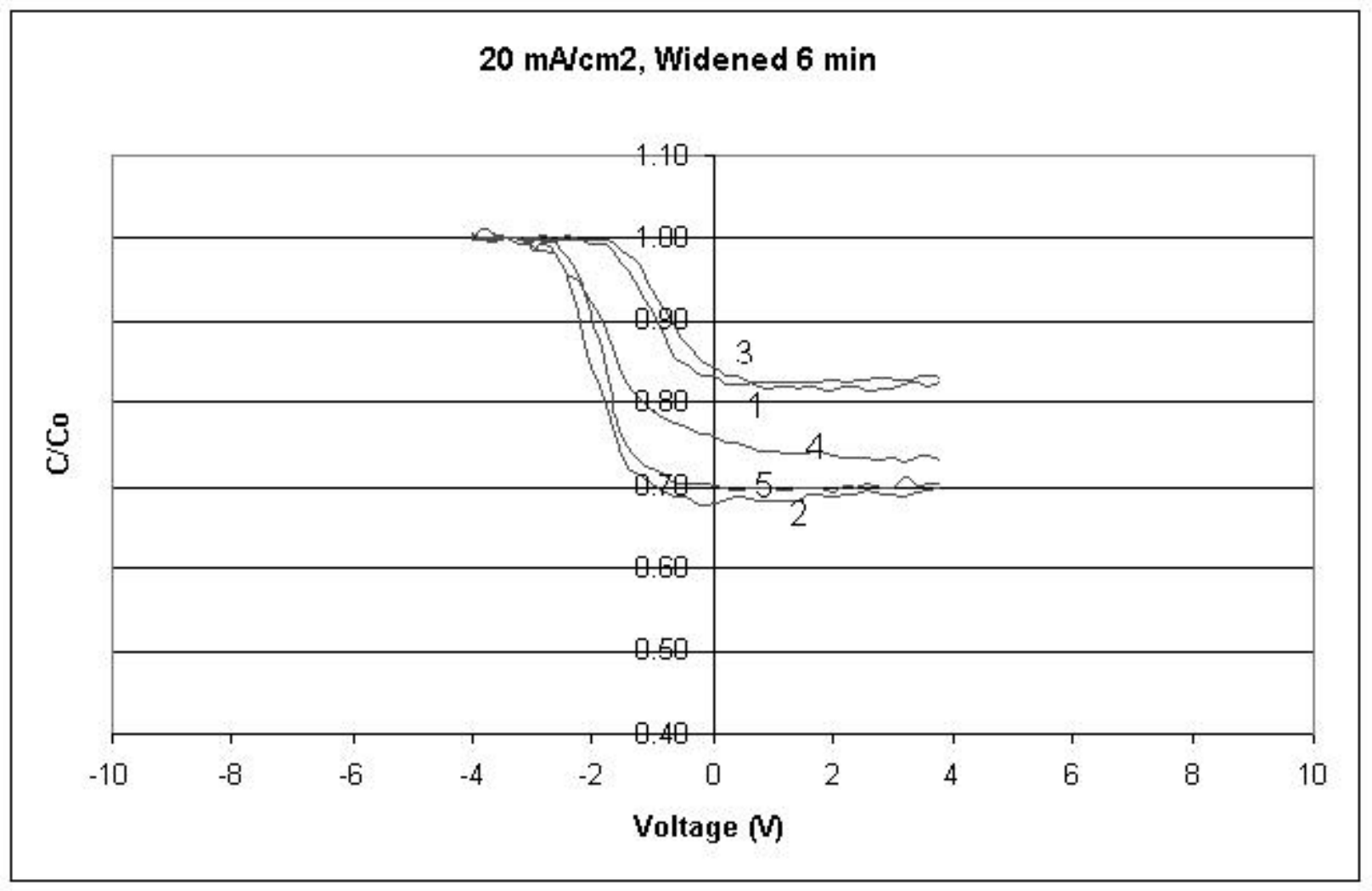

Figure $3.17-20 \mathrm{~mA} / \mathrm{cm}^{2}$, Pore Widened $6 \mathrm{~min}, \mathrm{Co}=300 \mathrm{pF}$

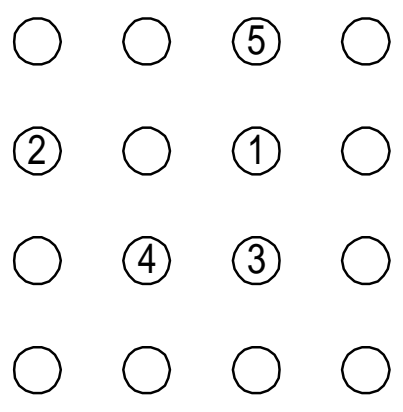

Figure 3.18 - Pad Layout, $20 \mathrm{~mA} / \mathrm{cm}^{2}$, Pore Widened 6 min 


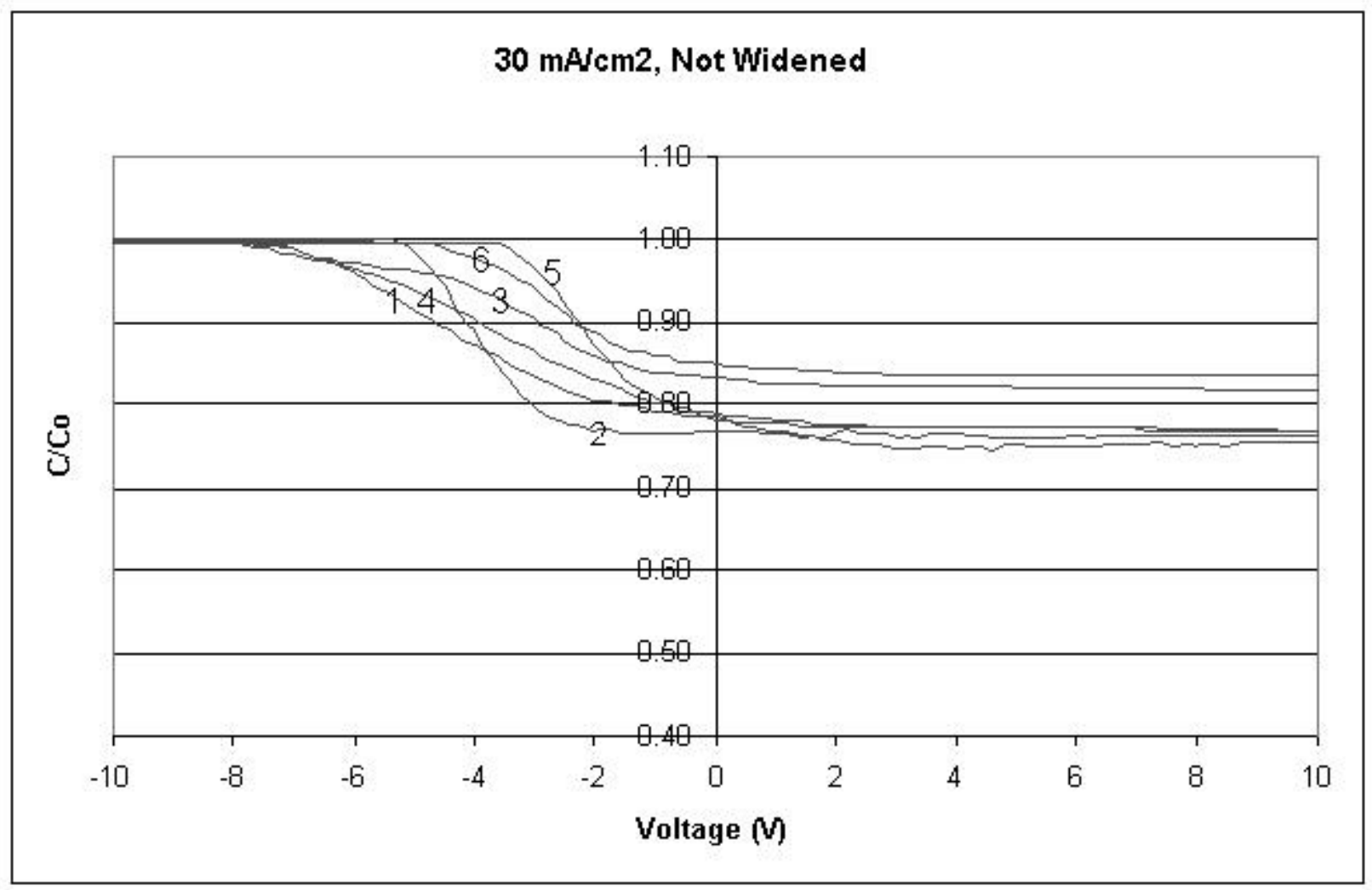

Figure 3.19 - $30 \mathrm{~mA} / \mathrm{cm}^{2}$, Not Pore Widened, Co $=178 \mathrm{pF}$ 


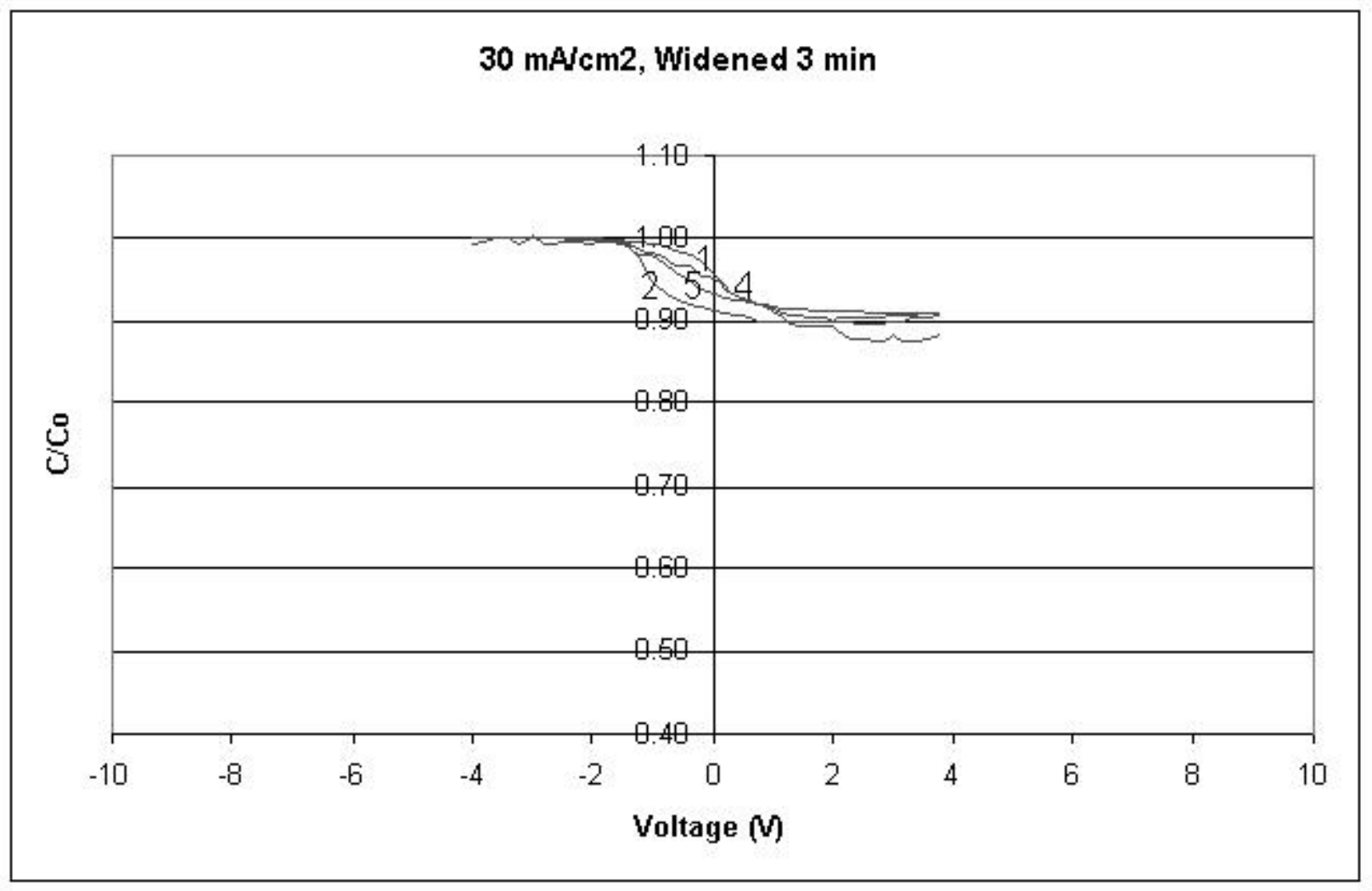

Figure $3.20-30 \mathrm{~mA} / \mathrm{cm}^{2}$, Pore Widened $3 \mathrm{~min}, \mathrm{Co}=70 \mathrm{pF}$

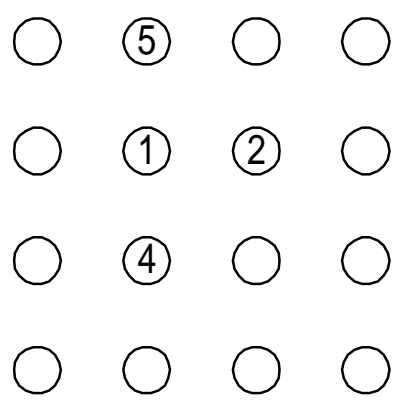

Figure 3.21 - Pad Layout, $30 \mathrm{~mA} / \mathrm{cm}^{2}$, Pore Widened $3 \mathrm{~min}$ 


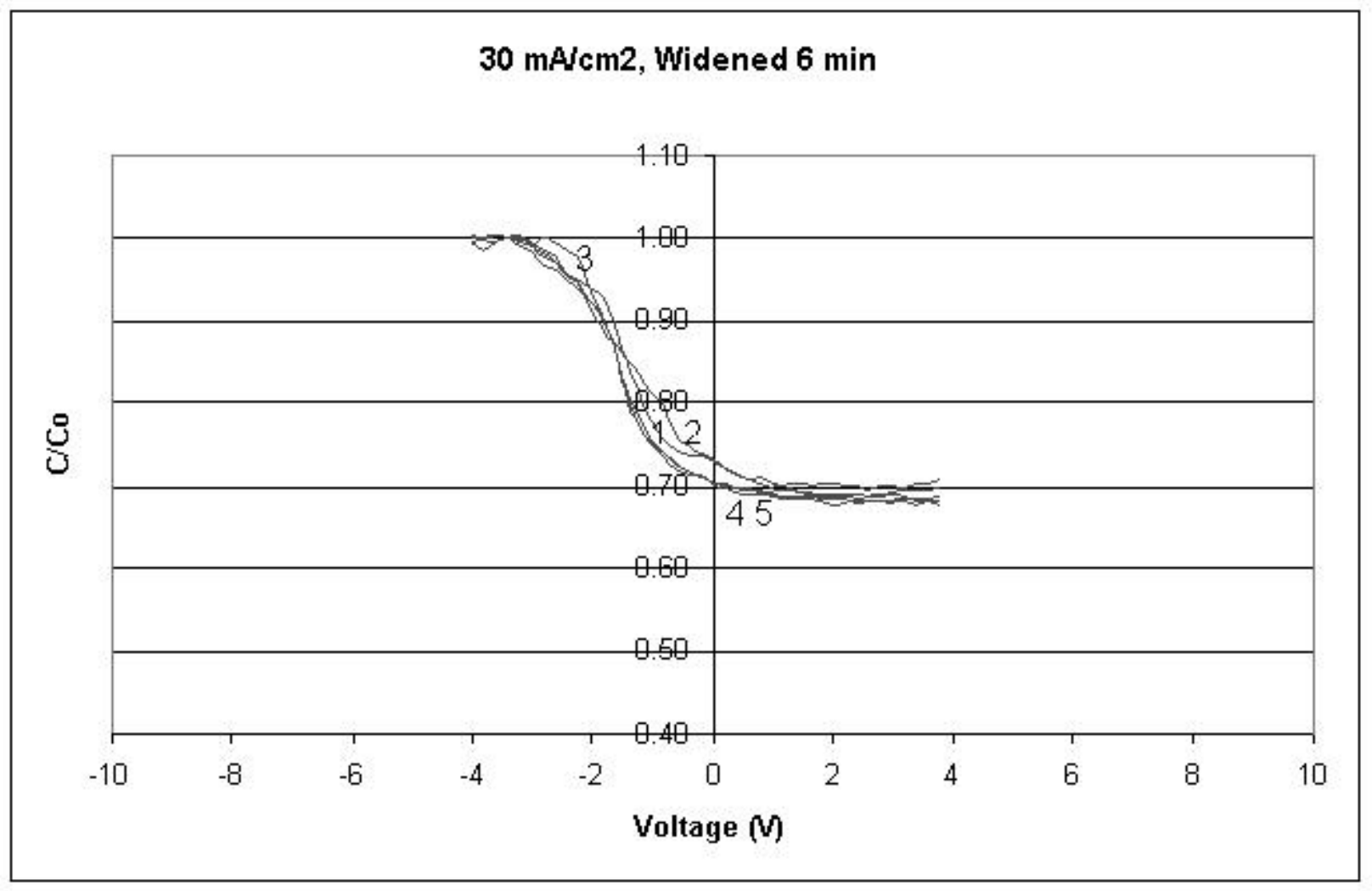

Figure $3.22-30 \mathrm{~mA} / \mathrm{cm}^{2}$, Pore Widened $6 \mathrm{~min}, \mathrm{Co}=320 \mathrm{pF}$

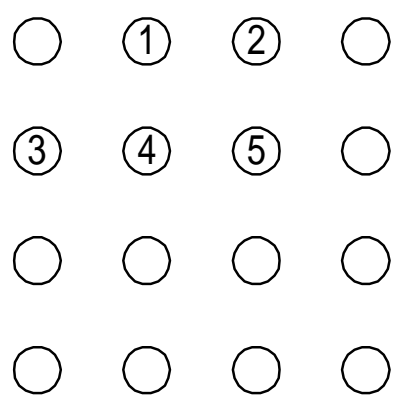

Figure 3.23 - Pad Layout, $30 \mathrm{~mA} / \mathrm{cm}^{2}$, Pore Widened $6 \mathrm{~min}$ 


\subsection{Discussion}

The CV data presented in the previous section were analyzed using a Matlab program developed for this project (Appendix A) to obtain the threshold voltage and flatband voltage of the devices. The carrier density of the substrate was also calculated and compared with the known substrate density for verification, which matched very well.

The threshold voltages obtained from the CV data are shown in Figure 3.24. In this research, threshold voltage $\left(V_{T H}\right)$ is defined as:

$$
V_{T H}=V\left(C_{i n v}+\left(C_{o}-C_{i n v}\right) \cdot 0.05\right)
$$

This is the voltage at which the capacitance drops to $5 \%$ of the difference between its maximum and minimum values.

For each anodization current density, the threshold voltages are plotted for different capacitor pad of the various samples: those not pore widened, those widened for 3 minutes, and those widened for 6 minutes. It may be noted that pore widening has a significant effect on threshold voltage distribution for samples anodized at $15 \mathrm{~mA} / \mathrm{cm}^{2}$. This is an important observation since lower current densities are typically used to obtain smaller pore diameters. For samples anodized at $20 \mathrm{~mA} / \mathrm{cm} 2$ and $30 \mathrm{~mA} / \mathrm{cm} 2$, the effect 
of pore widening on the threshold voltage distribution is not as obvious. However, pore widening of 3 minutes appears to produce lower variations in threshold voltages.

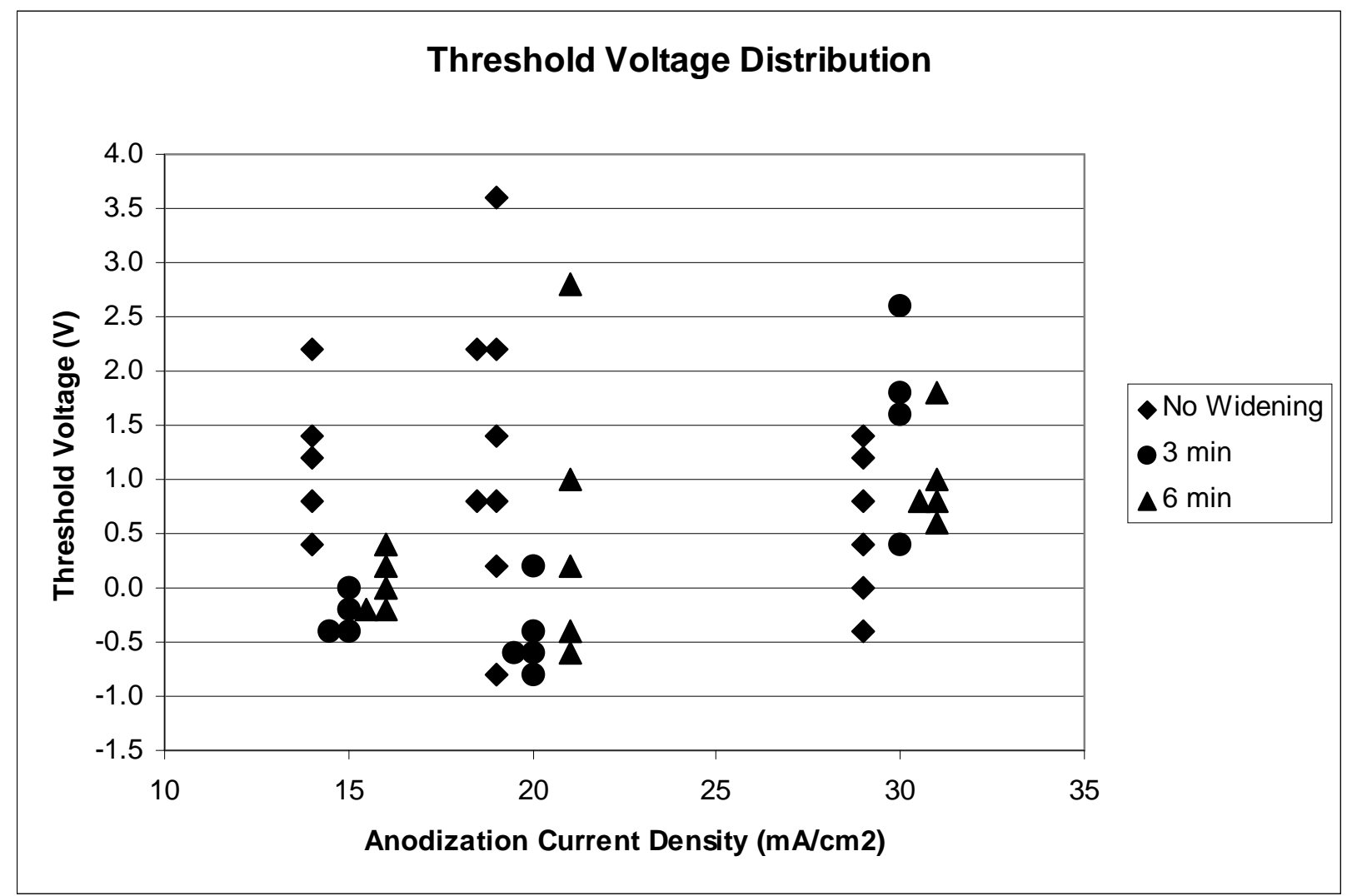

Figure 3.24 - Distribution of Threshold Voltage as a Function of Current Density

The CV data also show a distribution of the flatband voltage as shown in Figure 3.25.

Here, flatband voltage $\left(V_{F B}\right)$ was calculated using the expression:

$$
V_{F B}=V\left(C_{o}-\left(C_{o}-C_{\text {inv }}\right) \cdot 0.05\right)
$$


This is the voltage at which the capacitance drops to $95 \%$ of the difference between its maximum and minimum values.

Although the flatband voltage shows a large distribution, an average value for the porewidened samples was calculated to be -3.29 V. It can be seen from Figure 3.25 that the flatband voltage distribution is significantly reduced for the pore-widened samples. The improvement in $\mathrm{V}_{\mathrm{FB}}$ for the pore-widened samples is believed to be due to the removal of the impurity ions left by the anodization process. This is currently being verified by photoluminescent (PL) measurements on samples with and without pore-widening. The presence of impurities is expected to create a series of peaks on PL scans. Pore-widened samples should show a lower intensity at each of these peaks indicating the removal of these impurities. 


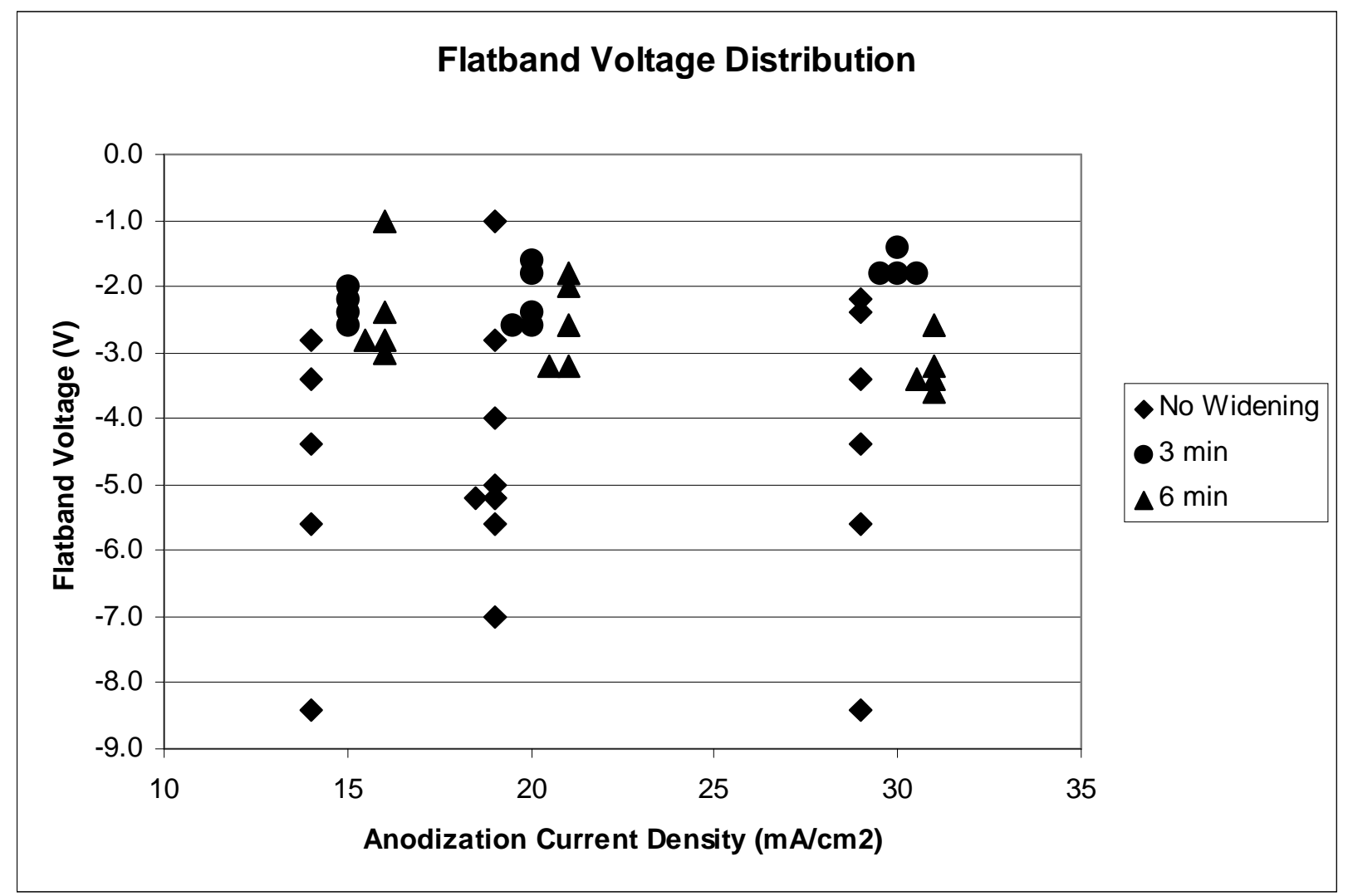

Figure 3.25 - Distribution of Flatband Voltage as a Function of Current Density

It is encouraging to note that similar characteristics have also been observed in capacitors formed on AlO:N insulators created by the oxidation of AlN thin films on silicon [25]. The AlO:N insulators, which are non porous, are being investigated as alternatives for $\mathrm{SiO}_{2}$. A flatband voltage of $\mathrm{V}_{\mathrm{FB}}=-2.723 \mathrm{~V}$ was obtained in [25], as shown in Figure 3.26 . 


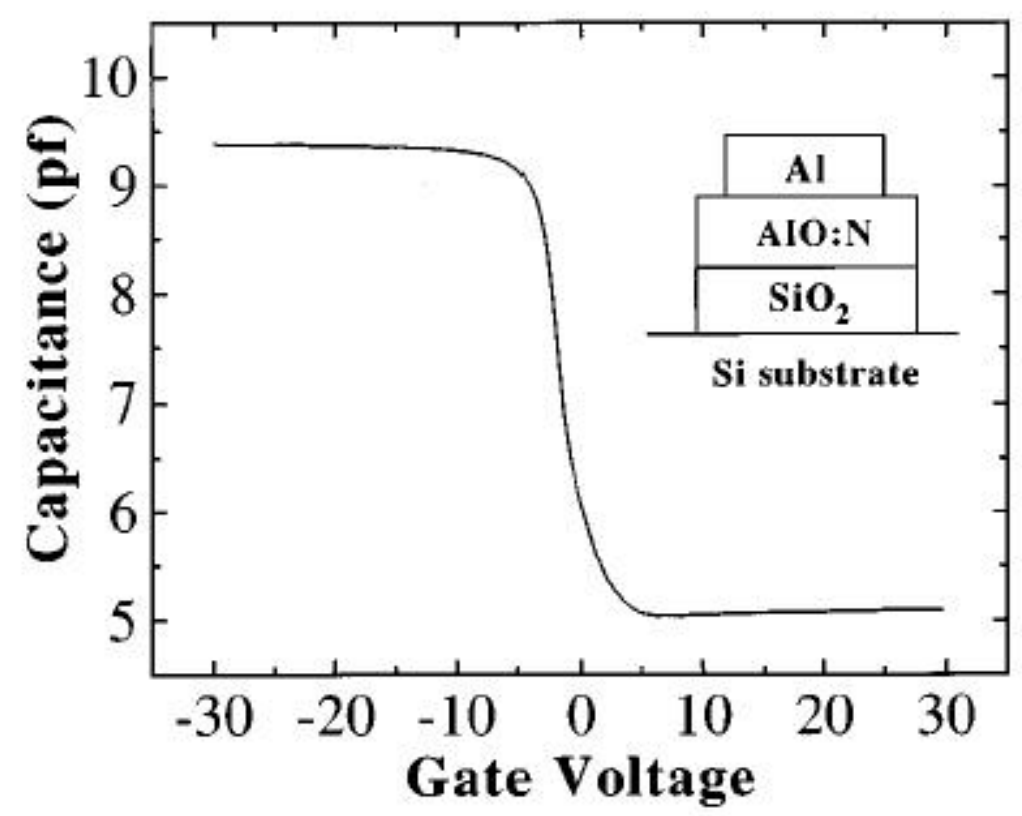

Figure 3.26 - C-V Curve of a $\mathrm{Al}_{2} \mathrm{O}_{3}$ Capacitor Created by the Oxidation of AIN [25]

It is, however, important to note that the devices investigated in this thesis use porous alumina structures created by electrochemical means, rather than crystalline arrangements grown by epitaxial methods.

After considering $\mathrm{C}_{\mathrm{o}}$ of each capacitor, it is simple to calculate the dielectric constant for each sample using the following relationship:

$$
\mathcal{E}_{r}=\frac{C_{o} \cdot t_{o x}}{\mathcal{E}_{o} \cdot A}
$$


where $C_{o}$ is the oxide capacitance $(\mathrm{F}), t_{o x}$ is the oxide thickness (m), and $A$ is the area of the top contact $\left(\mathrm{m}^{2}\right)$. The results are given in Table 3.2 below.

\begin{tabular}{|c|c|c|c|}
\hline $\begin{array}{c}\text { Current Density } \\
\left(\mathrm{mA} / \mathrm{cm}^{2}\right)\end{array}$ & Not Pore Widened & Pore Widened 3 min & Pore Widened 6 min \\
\hline 15 & $\mathrm{C}_{\mathrm{o}}=174 \mathrm{pF}$ & $\mathrm{C}_{\mathrm{o}}=300 \mathrm{pF}$ & $\mathrm{C}_{\mathrm{o}}=300 \mathrm{pF}$ \\
& $\varepsilon_{\mathrm{r}}=1.98$ & $\varepsilon_{\mathrm{r}}=3.42$ & $\varepsilon_{\mathrm{r}}=3.42$ \\
\hline 20 & $\mathrm{C}_{\mathrm{o}}=143 \mathrm{pF}$ & $\mathrm{C}_{\mathrm{o}}=260 \mathrm{pF}$ & $\mathrm{C}_{\mathrm{o}}=300 \mathrm{pF}$ \\
& $\varepsilon_{\mathrm{r}}=1.63$ & $\varepsilon_{\mathrm{r}}=2.96$ & $\varepsilon_{\mathrm{r}}=3.42$ \\
\hline 30 & $\mathrm{C}_{\mathrm{o}}=178 \mathrm{pF}$ & $\mathrm{C}_{\mathrm{o}}=70 \mathrm{pF}$ & $\mathrm{C}_{\mathrm{o}}=320 \mathrm{pF}$ \\
& $\varepsilon_{\mathrm{r}}=2.02$ & $\varepsilon_{\mathrm{r}}=0.80$ & $\varepsilon_{\mathrm{r}}=3.65$ \\
\hline
\end{tabular}

Table 3.2 - Calculated Dielectric Constants of Capacitors

It is interesting to note in Table 3.2 that the relative dielectric constant increases after pore-widening has been performed. The only instance where this does not occur is for the sample that was anodized at $30 \mathrm{~mA} / \mathrm{cm}^{2}$, and pore-widened for 3 minutes. It is important to note that this sample was damaged before measurement, and is included for the purposes of completion, and thus it may be disregarded.

The change of dielectric constant exhibited by the templates after pore-widening indicates a change in pore geometry due to the process. Although pore-widening slowly increases the diameter of the template pores, the increase in oxide capacitance (and therefore the relative dielectric constant) may at first seem contradictory. The explanation for this phenomenon is that the plates of the capacitor (the Si substrate and the $\mathrm{Al}$ top contact) are closer together in pore-widened samples. The reason for this is that when the $\mathrm{Al}$ top contact is sputtered onto unwidened samples, it creates a semiuniform covering across the pores. In pore-widened samples, however, impurities inside 
the pores are drastically reduced, and the $\mathrm{Al}$ top contact deposits partially inside the pore during the sputtering process (Figure 3.27).
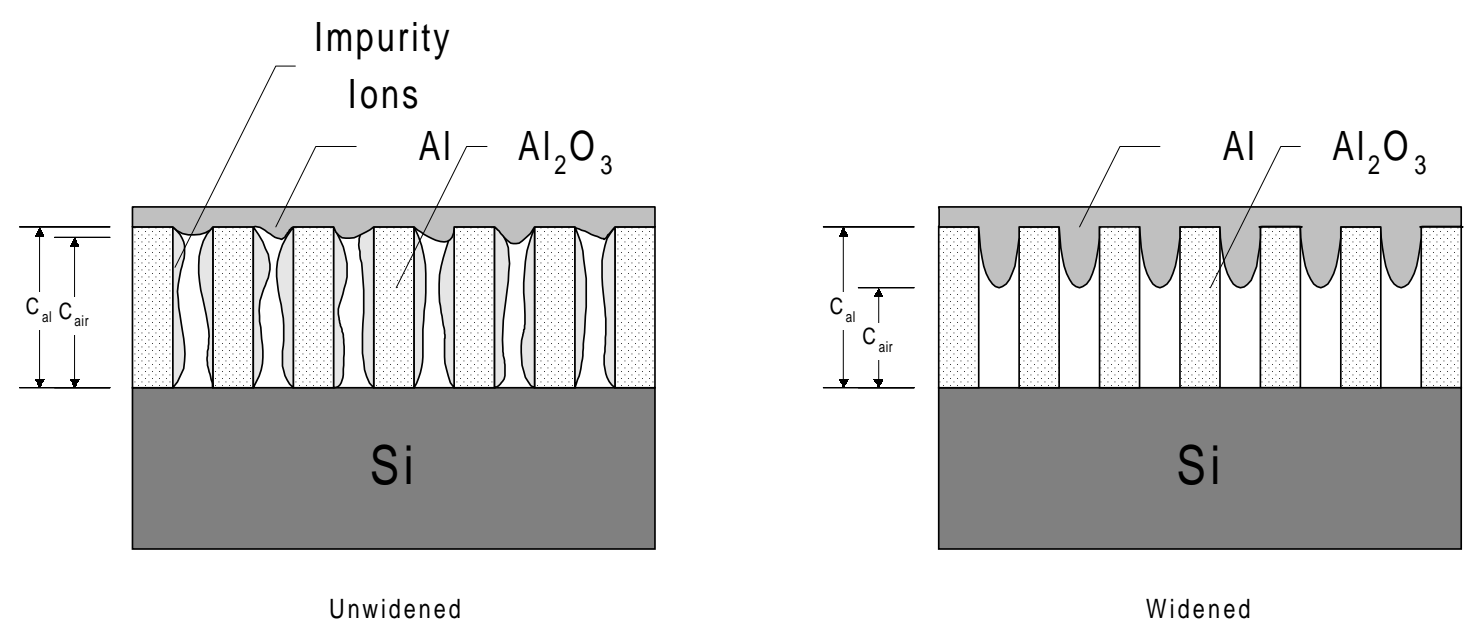

Figure 3.27 - Effects of Pore Widening on Geometry

Although the oxide is a complex porous structure, the total capacitance, $C_{o}$, may be approximated as two capacitances in parallel. Therefore,

$$
C_{o}=C_{a i r}+C_{a l}
$$

where $C_{o}(\mathrm{~F})$ is the total capacitance, $C_{a i r}(\mathrm{~F})$ is the capacitance due to the air-filled pores, and $C_{a l}(\mathrm{~F})$ is the capacitance due to the alumina pore walls. Since the walls are constructed of alumina, with a dielectric constant of approximately $\varepsilon_{\mathrm{al}}=9.7$, and the pores are filled with air, with a dielectric constant $\varepsilon_{\text {air }}=1.0$ : 


$$
C_{o}=\frac{\varepsilon_{a i r} \cdot \varepsilon_{o} \cdot A_{a i r}}{t_{a i r}}+\frac{\varepsilon_{a l} \cdot \varepsilon_{o} \cdot A_{a l}}{t_{a l}}
$$

By microscopic inspection of devices, it is noted that the porosity, $P$ (ratio of pores to total area), is quite high. It is also known that the thickness of alumina ( $\left.\mathrm{t}_{\mathrm{al}}\right)$ existing after anodization is at least $200 \mathrm{~nm}$. And finally, it is known that the thickness of the air layer is less than that of the alumina layer.

If these three quantities are considered across a short range, viable measurements of pore dimensions may be estimated using the relationship above. This was performed using Matlab code, shown in Appendix B. The resulting plots for samples anodized at 15, 20, and $30 \mathrm{~mA} / \mathrm{cm}^{2}$ appear in Figures 3.28, 3.29, and 3.30, respectively. 


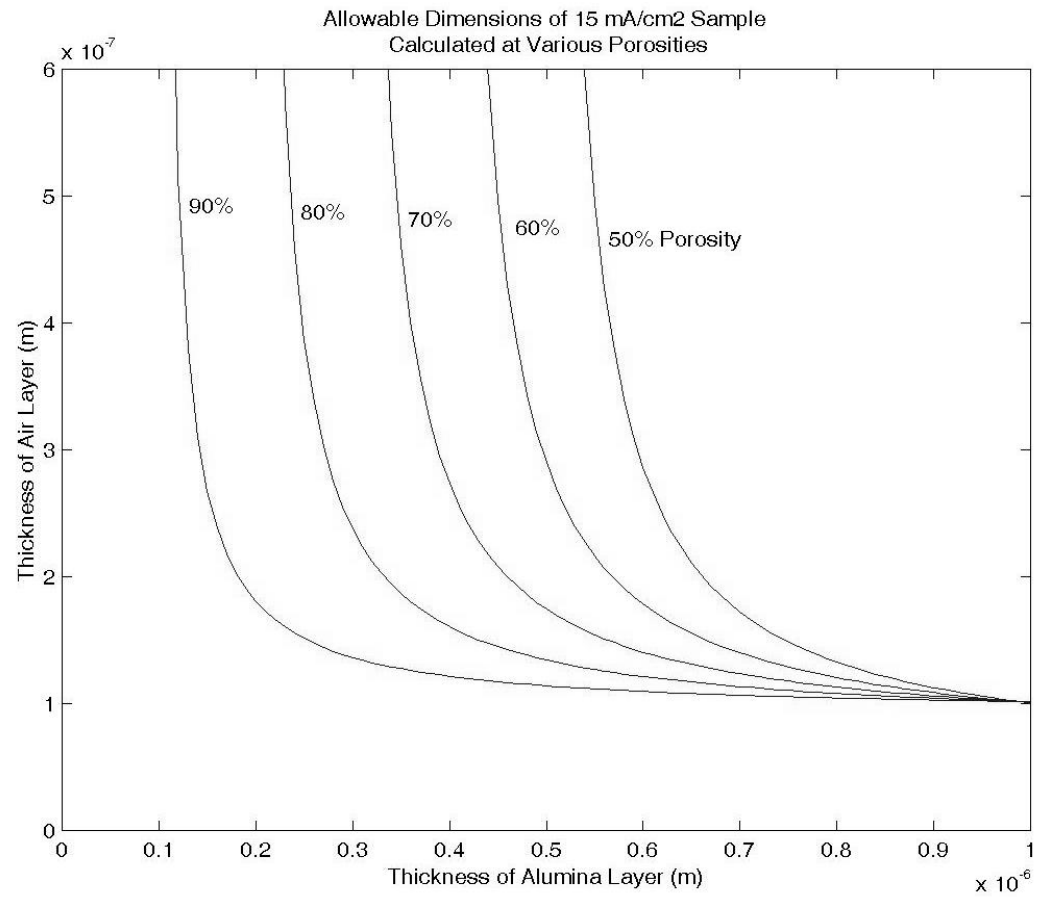

Figure 3.28 - Pore Geometry Estimation for $15 \mathrm{~mA} / \mathrm{cm}^{2}$ Sample

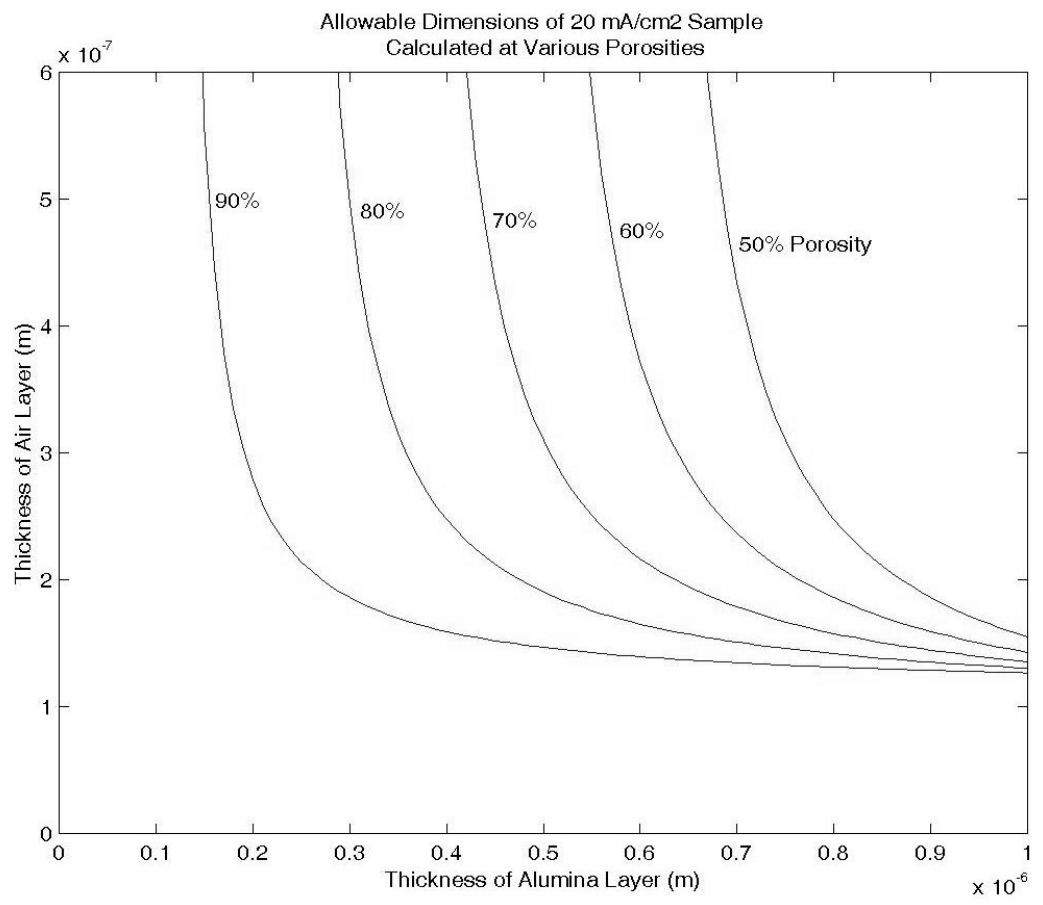

Figure 3.29 - Pore Geometry Estimation for $20 \mathrm{~mA} / \mathrm{cm}^{2}$ Sample 


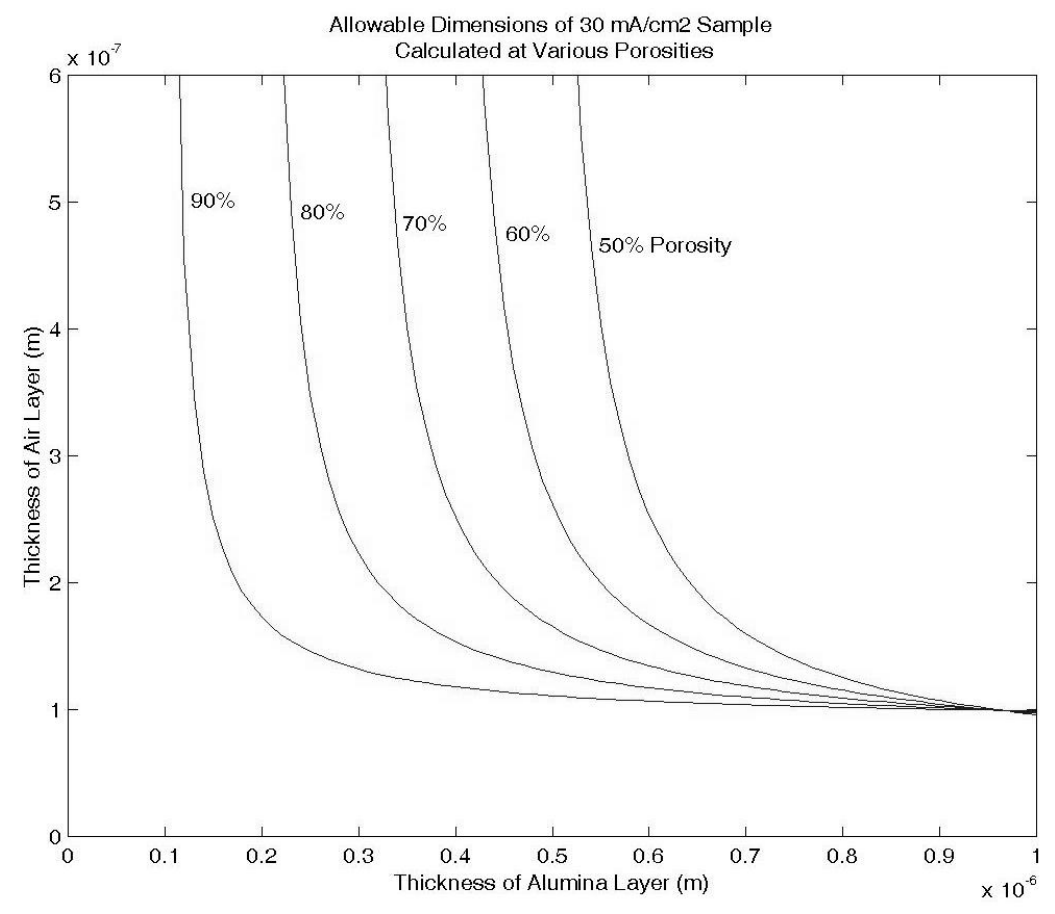

Figure 3.30 - Pore Geometry Estimation for $30 \mathrm{~mA} / \mathrm{cm}^{2}$ Sample 
It can be seen from Figures 3.28 through 3.30 that for a selected thickness of the alumina and air layers, the porosity of the template increases with an increase in anodization current density, as expected. Porosity is expected to increase linearly as a function of anodization potential, as indicated by other studies [21].

Since the alumina layer is know to be between 200 and $300 \mathrm{~nm}$, and the air layer is known to be thinner than the alumina layer in these pore-widened samples, we may place boundary conditions upon these relations. These conditions are shown in Figures 3.31 through 3.33. The region of valid estimation is contained in the trapezoid bounded by the conditions $\mathrm{x}>200 \mathrm{E}-9, \mathrm{x}<300 \mathrm{E}-9, \mathrm{y}<\mathrm{x}$, and of course $\mathrm{y}>0$; where $\mathrm{x}$ is the thickness of the alumina layer in meters, and $y$ is the thickness of the air layer in meters.

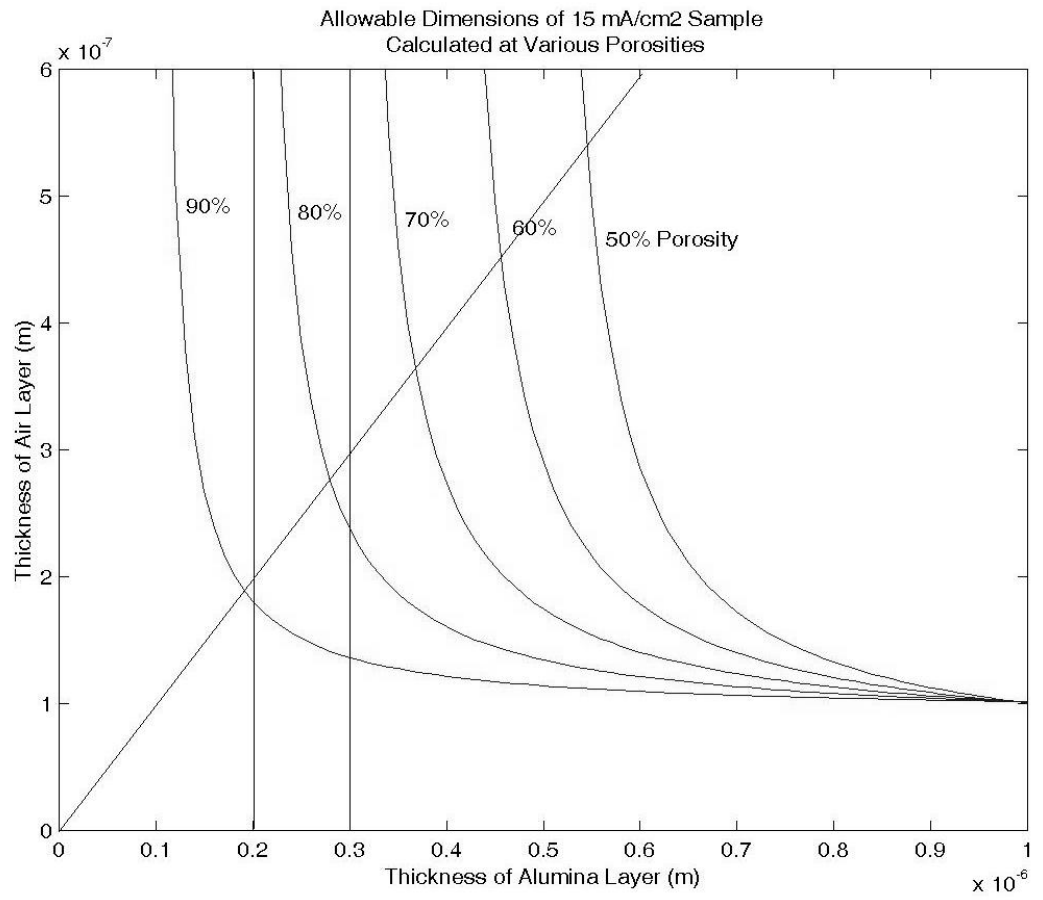

Figure 3.31 - Viable Dimensions of Pores of $15 \mathrm{~mA} / \mathrm{cm}^{2}$ Sample 


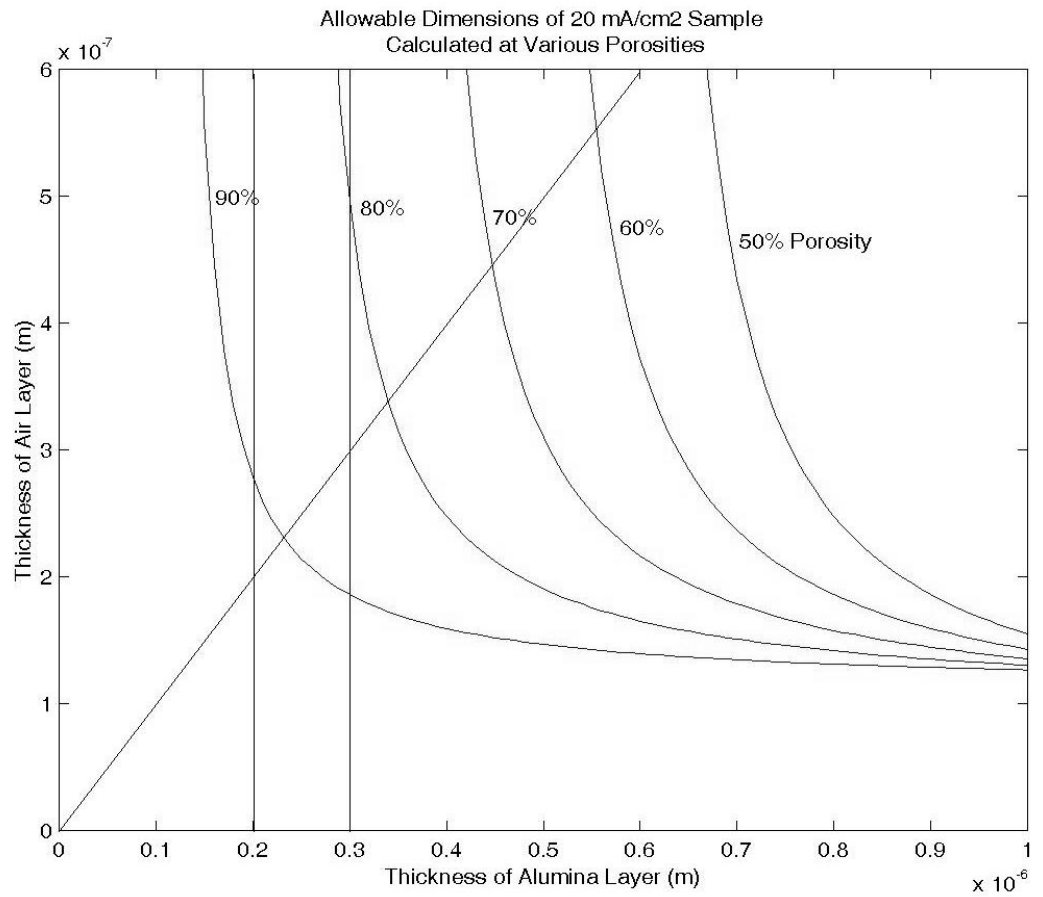

Figure 3.32 - Viable Dimensions of Pores of $20 \mathrm{~mA} / \mathrm{cm}^{2}$ Sample

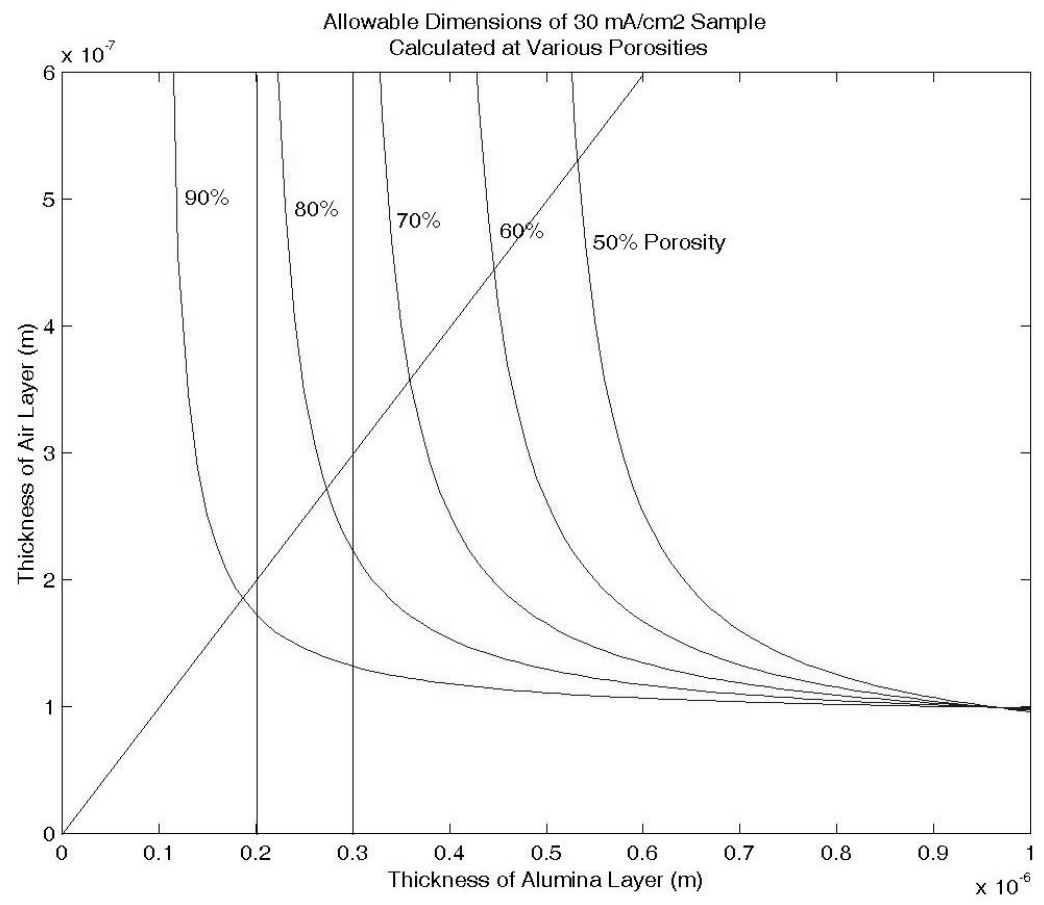

Figure 3.33 - Viable Dimensions of Pores of $30 \mathrm{~mA} / \mathrm{cm}^{2}$ Sample 
By examining these graphs, we can see that the porosity in each of the pore-widened samples is at least $77 \%$. If the thickness of the alumina layer is fixed at $200 \mathrm{~nm}$ (as is expected to be the case) we see that the porosity of the nanostructures is even higher.

It is also interesting to note that in each case, as the thickness of the alumina is increased, the thickness of the air layer approaches an asymptote near $100 \mathrm{~nm}$. Therefore, regardless of the actual porosity, the air layer is at least $100 \mathrm{~nm}$ thick. It may be thus inferred that the aluminum top contact, which is sputter deposited on top of the pores, enters the pores by no more than $100 \mathrm{~nm}$. This number seems reasonable from prior experience, although verification for these particular samples was not performed because of imaging limitations. 


\subsection{Fabrication of Nickel Nanostructures}

The Nanostructures Research Group has recently established collaboration with the NASA Glenn Research Center to investigate the use of nickel nanostructures for preferential synthesis of carbon nanotubes on Silicon Carbide (SiC) substrates. The nickel nanostructures will be synthesized electrochemically on silicon carbide substrates using the template-based fabrication technique. The objective of this thesis was to develop the process steps for the synthesis of nickel nanostructures. Due to the high cost of $\mathrm{SiC}$ substrates, silicon wafers were used as substrates in this thesis. The technique will be transferred to $\mathrm{SiC}$ substrates once the process steps are finalized.

Electrochemical synthesis was considered the preferred technique for the deposition of the nickel nanostructures since the electric current flow would be concentrated through the pores. The fabrication process development involves two steps: (i) experimental determination of nickel deposition rate, and (ii) the deposition of nickel inside the template pores. They are described in the following sections.

\subsection{Electrochemical Deposition of Nickel}

Electrochemical deposition of nickel was performed in an apparatus similar to the anodization apparatus, with the platinum cathode replaced by a nickel anode. A dedicated apparatus similar to the 'Aperture Exposure Immersion' system described in 
section 2.3 was developed for this purpose to avoid contamination. The ion bath used is a solution of $800 \mathrm{ml}$ of de-ionized $\mathrm{H}_{2} \mathrm{O}$ containing $240 \mathrm{~g}$ of $\mathrm{NiSO}_{4}, 36 \mathrm{~g}$ of $\mathrm{NiCl}_{2}$, and $24 \mathrm{~g}$ of $\mathrm{H}_{3} \mathrm{BO}_{3}$. The powdered chemicals were carefully dissolved in DI water and heated to a temperature of $60 \mathrm{C}$ on a hot plate. A magnetic stirrer was used to maintain a uniform temperature. Silicon substrates coated with $100 \mathrm{~nm}$ thick top films of aluminum were used for the experimental determination of nickel deposition rate. An aluminum back contact on the silicon substrate acted as the cathode. The samples were mounted on the apparatus, which was then immersed in the solution. Electrodeposition was performed by exciting a constant current. The samples were then thoroughly rinsed in $\mathrm{DI}_{2} \mathrm{O}$ and dried with $\mathrm{N}_{2}$ gas.

\subsection{Deposition Rate Characterization}

For varying deposition current densities and durations, the supply of electrons, $N_{e}(\mathrm{~mol})$, to the reaction can be calculated by the relation

$$
N_{e}=\frac{A \cdot J \cdot t}{N_{a} \cdot e_{c}} \quad(\mathrm{~mol})
$$

where $A$ is the deposition area $\left(\mathrm{m}^{2}\right), J$ is the deposition current density $\left(\mathrm{A} / \mathrm{cm}^{2}\right), t$ is the reaction duration (s), $N_{a}$ is Avogadro's number $\left(\mathrm{mol}^{-1}\right)$, and $e_{c}$ is the charge on a single electron (C). Since each $\mathrm{Ni}^{+2}$ ion requires 2 electrons to create $\mathrm{Ni}$ :

$$
N i^{+2}+2 e^{-} \rightarrow N i
$$


the number of Ni atoms, $N_{n i}$, that deposit will be one half of the number of available electrons, $N_{e}$ :

$$
N_{N i}=\frac{N_{e}}{2} \quad(\mathrm{~mol})
$$

The expected number of deposited atoms and corresponding deposited mass is given for several reactions in Table 4.1 below.

\begin{tabular}{|c|c|c|c|}
\hline $\begin{array}{c}\text { Current Density } \\
\left(\mathrm{mA} / \mathrm{cm}^{2}\right)\end{array}$ & $\begin{array}{c}\text { Deposition Time } \\
(\mathrm{s})\end{array}$ & $\begin{array}{c}\text { Ni Ions Deposited } \\
(\mu \mathrm{mol})\end{array}$ & $\begin{array}{c}\text { Deposition Mass } \\
(\mu \mathrm{g})\end{array}$ \\
\hline 7 & 300 & 14.0 & 822 \\
\hline 14 & 90 & 8.4 & 493 \\
\hline 20 & 90 & 11.7 & 687 \\
\hline
\end{tabular}

Table 4.1 - Expected Depositions of Various Reactions

From these masses, and given the density of $\mathrm{Ni}\left(D_{N i}=8.908 \times 10^{6} \mathrm{~g} / \mathrm{m}^{3}\right)$ and the deposition area $\left(1.28 \times 10^{-4} \mathrm{~m}^{2}\right)$, it is straightforward to calculate the thickness, $T(\mathrm{~m})$, of the Ni film:

$$
T=\frac{M}{A \cdot D_{N i}} \quad(m)
$$

where $M$ is the deposited mass $(\mathrm{g})$, and $A$ is the deposition area $\left(\mathrm{m}^{2}\right)$. 
The calculated thickness for each reaction is given in Table 4.2 below.

\begin{tabular}{|c|c|c|c|}
\hline $\begin{array}{c}\text { Current Density } \\
\left(\mathrm{mA} / \mathrm{cm}^{2}\right)\end{array}$ & $\begin{array}{c}\text { Deposition Time } \\
(\mathrm{s})\end{array}$ & $\begin{array}{c}\text { Deposited Thickness } \\
(\mathrm{nm})\end{array}$ & $\begin{array}{c}\text { Deposition Rate } \\
(\mathrm{nm} / \mathrm{s})\end{array}$ \\
\hline 7 & 300 & 721 & 2.39 \\
\hline 14 & 90 & 432 & 4.81 \\
\hline 20 & 90 & 603 & 6.70 \\
\hline
\end{tabular}

Table 4.2 - Expected Thickness of Various Deposition Reactions

Electrodeposition of nickel was then performed as demonstrated by each of the reactions outlined above. Deposition times were varied from $90 \mathrm{~s}$ to $300 \mathrm{~s}$. The thickness of the deposited nickel film was measured using an Alpha Step. The results are summarized in Table 4.3 shown below.

\begin{tabular}{|c|c|c|c|c|}
\hline Sample Number & $\begin{array}{c}\text { Current Density } \\
\left(\mathrm{mA} / \mathrm{cm}^{2}\right)\end{array}$ & $\begin{array}{c}\text { Deposition } \\
\text { Time }(\mathrm{sec})\end{array}$ & $\begin{array}{c}\text { Ni Thickness } \\
(\mathrm{nm})\end{array}$ & $\begin{array}{c}\text { Deposition Rate } \\
(\mathrm{nm} / \mathrm{s})\end{array}$ \\
\hline 041701C & 20 & 90 & 110 & 1.222 \\
\hline 041701D & 14 & 90 & 70 & 0.777 \\
\hline 041701E & 7 & 300 & 40 & 0.133 \\
\hline
\end{tabular}

Table 4.3 - Results of Electroplating Experimentation

The deposition rate of nickel calculated from Table 4.3 is plotted as a function of current density in Figure 4.1. 
The experimental growth rate, $R(\mathrm{~nm} / \mathrm{s})$, of electrodeposited nickel film on an area of $1.28 \mathrm{~cm}^{2}$ can be determined from the following relationship:

$$
R=0.084 \cdot J-0.453
$$

where $J$ is the current density in $\mathrm{mA} / \mathrm{cm}^{2}$.

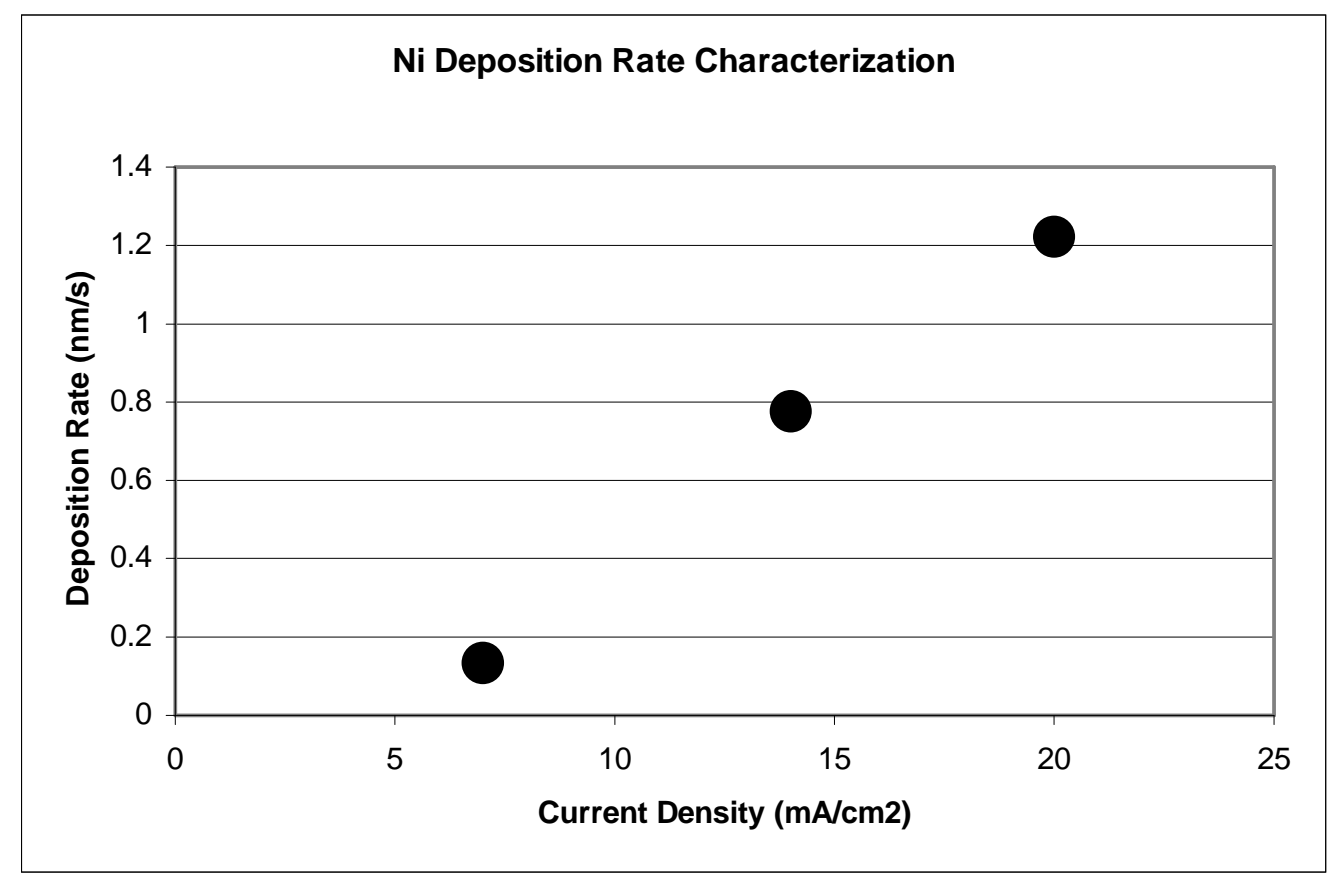

Figure 4.1 - Electroplating Deposition Rate of Ni

Photographs of the samples used to perform this analysis are shown in Figures 4.2 through 4.5. 


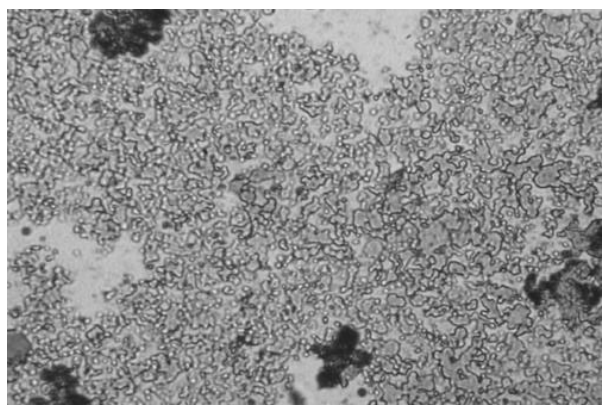

Figure 4.2 - Sample 041701B

$14 \mathrm{~mA} / \mathrm{cm}^{2}, 90 \mathrm{~s}, 85 \mathrm{~nm}$ film, $125 \mathrm{x}$ magnification

Displays nonuniformity with impurities, regions of localized clumping and areas where plating does not occur.

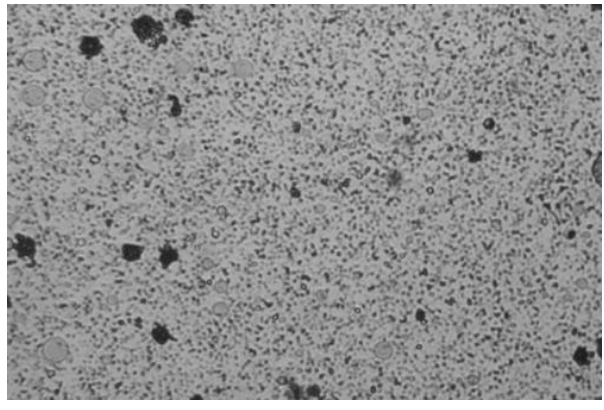

Figure 4.3 - Sample 041701C

$20 \mathrm{~mA} / \mathrm{cm}^{2}, 90 \mathrm{~s}, 110 \mathrm{~nm}$ film, $125 \mathrm{x}$ magnification

Displays regular coverage with slight variations in grain size.

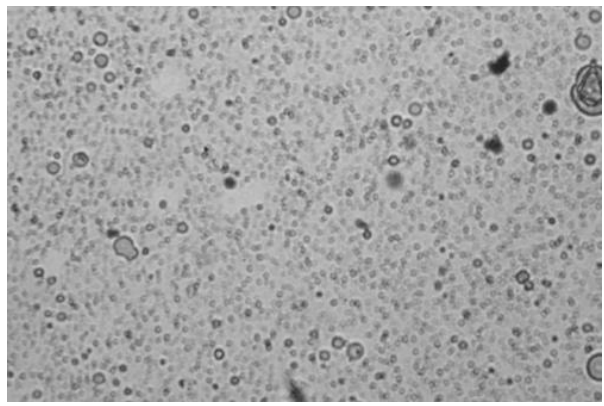

Figure 4.4 - Sample 041701D

$14 \mathrm{~mA} / \mathrm{cm}^{2}, 90 \mathrm{~s}, 70 \mathrm{~nm}$ film, $125 \mathrm{x}$ magnification

Displays highly regular grain size with few impurities and very few regions of low coverage.

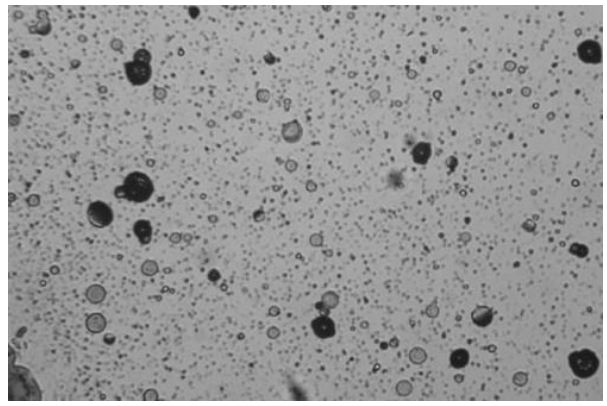

Figure 4.5 - Sample 041701E

$7 \mathrm{~mA} / \mathrm{cm}^{2}, 300 \mathrm{~s}, 40 \mathrm{~nm}$ film, $125 \mathrm{x}$ magnification

Displays uneven coverage with localized clumping. 


\subsection{Discussion}

Although the expected and actual deposition rates of Ni do not agree exactly, they do show that a linear relation exists. Several factors may explain these differences. The empirical equations used for estimation do not account for the losses due to electrode potentials or impurities in the solution. This fact helps to explain the offset of the current density displayed by the experimental data, which suggests the existence of a small activation energy required to overcome these potentials.

\subsection{Synthesis of Nickel Nanostructures}

Once several processes were performed on bare Si wafers and an approximate deposition rate was obtained, nickel nanostructures were created in anodized alumina templates. Since each pore has a lower resistance that the surrounding alumina structure, the flow of $\mathrm{Ni}^{+2}$ ions is localized to these areas. The ions enter each of the pores and deposit when they encounter the Si interface at the bottoms.

Samples were deposited at a current density of $10 \mathrm{~mA} / \mathrm{cm}^{2}$ to provide the best results, as indicated by preliminary experiments. All samples exhibited visual indications that deposition was successful - a Ni film was easily seen on each by the unaided eye. The samples are currently awaiting further imaging. 


\subsection{Summary and Conclusions}

At the beginning of this project, a great deal of time was spent in designing an improved apparatus to facilitate faster processing of samples for the work ahead. An inexpensive system was devised that is easy to use and produces dependable samples. As a result, device throughput of the Nanostructures Research Lab has increased more than tenfold, along with an increase in safety and a decrease in chemical usage.

Preliminary electrical characterization by capacitance-voltage measurement predicted that device parameters could be obtained to complement other characterizations. It was also demonstrated that alumina-based MOS devices created in this project are comparable to those designed in other facilities, with more established techniques.

Once the quality of the oxide templates was proven, the ability to synthesize semiconductor nanostructures within the pores was demonstrated by the electrochemical deposition of nickel. This simple procedure shows the possibilities that exist for creating complex devices in nanoscale dimensions. 


\subsection{Future Work}

To expand upon the research presented here, it is suggested to explore several areas in future work. First, it would be useful to correlate the CV measurement data with photoluminescent measurements on pore-widened templates. This would give a better understanding of the effect of pore-widening and help to support the hypothesis that the process removes or reduces impurity ions in the pores. Second, the CV measurements could be extended to devices fabricated on SiC substrates. By closely examining the data presented herein, it would be elementary to migrate to this new substrate type. Third, the Ni deposited inside pores should be characterized by microscopy to validate the predictions made in this thesis. Once this is complete, it would be incremental to fabricate Ni nanostructures on $\mathrm{SiC}$ substrates. 


\subsection{Bibliography}

[1] S. P. McGinnis and B. Das; A novel technique for fabricating semiconductor nanodevice arrays on silicon, IEEE/Cornell Conference on Advanced Concepts in High Speed Semiconductor Devices and Circuits, Ithaca, NY (1995).

[2] B. Das and S. P. McGinnis; Novel template based semiconductor nanostructures and their applications, Applied Physics A, 71, 681-688 (2000).

[3] D. Routkevitch, T. Bigioni, M. Moskovits, and X. Jing Ming; Electrochemical fabrication of $\mathrm{CdS}$ nanowire arrays in porous anodic aluminum oxide templates, Journal of Physical Chemistry, 100, 14037-47 (1996).

[4] D. N. Davydov, P. A. Sattari, D. Al Mawlawi, A. Osika, L. Haslett, and M. Moskovits; Field emitters based on porous aluminum oxide templates, Journal of Applied Physics, 86, 3983-7 (1999).

[5] D. N. Davydov, J. Haruyama, D. Routkevitch, B. W. Statt, D. Ellis, M. Moskovits, and J. M. Xu; Nonlithographic nanowire-array tunnel device: fabrication, zero-bias anomalies, and Coulomb blockade, Physical Review B (Condensed Matter), 57, 13550-3, (1998). 
[6] D. Al Mawlawi, C. Douketis, T. Bigioni, M. Moskovits, D. Routkevitch, L. Ryan, T. Haslett, A. Williams, and X. Jing Ming; Electrochemical fabrication of metal and semiconductor nano-wire arrays, Proceedings of the Symposium on Nanostructured Materials in Electrochemistry, (1995).

[7] J. C. Hulteen, V. P. Menon, and C. R. Martin; Template preparation of nanoelectrode ensembles: achieving the 'pure-radial' electrochemical-response limiting case, J. Chem Soc., Faraday Trans., 92, 4029-4032, (1996).

[8] L. T. Canham; Silicon quantum wire array fabrication by electrochemical and chemical dissolution of wafers, Appl. Phys. Lett., 57, 10, 1046-50 (1990).

[9] L.T. Canham, T.I. Cox, A. Loni, and A.J. Simons; Progress towards silicon optoelectronics using porous silicon technology, Proc. 1995 Symp. Si Heterostructures, Applied Surface Science, 102, 436 (1996).

[10] R.T. Collins, P.M. Fauchet, and A.M. Tischler; Porous silicon: from luminescence to LEDs, Physics Today, 50, 24 (1997).

[11] M. Balukani, S. LaMonica and A. Ferrari; $200 \mathrm{MHz}$ optical signal modulation from a porous silicon light emitting device, App. Phys. Lett., 72, 639 (1998). 
[12] S. Lazarouk, P. Jaguiro and V. Borisenko; Integrated opto-electronic unit based on porous silicon, Physica Status Solidi 165, 87 (1998).

[13] L. Pavesi; Porous silicon based light emitting diodes : A progress report, Physica Status Solidi 165, 91 (1998).

[14] C. Garman, S. P. McGinnis, P. Sines, and B. Das; An improved automated anodization apparatus for fabricating nanostructure devices and porous silicon, Rev. of Sci. Inst., 72, 1, 275-7 (2001).

[15] S.P. McGinnis, J.N. Cleary and B. Das; Fabrication of semiconductor nanostructure arrays on a silicon substrate using an anodized aluminum template, Materials Research Society Symposium Proceedings: Advances in Microcrystalline and Nanocrystalline Semiconductors, 452, 299-303 (1996).

[16] S.P. McGinnis and B. Das; A Novel technique for fabricating semiconductor nanodevice arrays on silicon, Proceedings of the IEEE Cornell Conference on Advanced Concepts in High Speed Semiconductor Devices and Circuits, 179-188 (1995).

[17] B. Das and S. McGinnis; Novel Template Based Semiconductor Nanostructures and their Applications, J. App. Phys. (in review). 
[18] B. Das and S.P. McGinnis; Ultrafast x-ray detectors based on semiconductor nanostructures, SPIE International Symposium on Medical Imaging, Feb. 1996.

[19] Jessensky O., Muller F., Gosele U.; Self-organized formation of hexagonal pore structures in anodic alumina, J. Electrochemicals Society 145, 3737-3740 (1998).

[20] A.P. Li, F. Muller, A. Birner, K. Nielsch, and U. Gosele; Hexagonal pore arrays with a 50-420 nm interpore distance formed by self-organization in anodic alumina, J. Appl. Phys. 84 6023-6026 (1998).

[21] D. Crouse, Yu-Hwa Lo, A. E. Miller, and M. Crouse; Self-ordered pore structure of anodized aluminum on silicon and pattern transfer, App. Phys. Lett. 76, 49-51 (2000).

[22] Masuda H., Hawegwa F., Ono S.; Self-ordering of cell arrangement of anodic porous alumina formed in sulfuric acid solution, Journal of the Electrochemical Society 144, L127-L130 (1996).

[23] D. Routkevitch, A.A. Tager, J. Haruyama, and D. Almawlawi; Nonlithographic nano-wire arrays: Fabrication, physics, and device applications, IEEE Transactions on Electron Devices 43,1646-1658 (1996). 
[24] O. Jessensky, F. Muller, and U. Gosele; Self-organized formation of hexagonal pore structures in anodic alumina, Journal Of Electrochemical Society, vol. 145, pp. 3735-40, (1998).

[25] E. A. Chowdhury, J. Kolodzey, J. O. Olowolafe, G. Qiu, G. Katulka, D. Hits, M.

Dashiell, and D. van der Weide; Thermally oxidized AlN thin films for device insulators, Appl. Phys. Lett., 70, (1997). 


\subsection{Appendices}

These appendices contain information that is supplemental to the research conducted herein. Details of the equipment, source code, and procedures are given to facilitate further work in these areas.

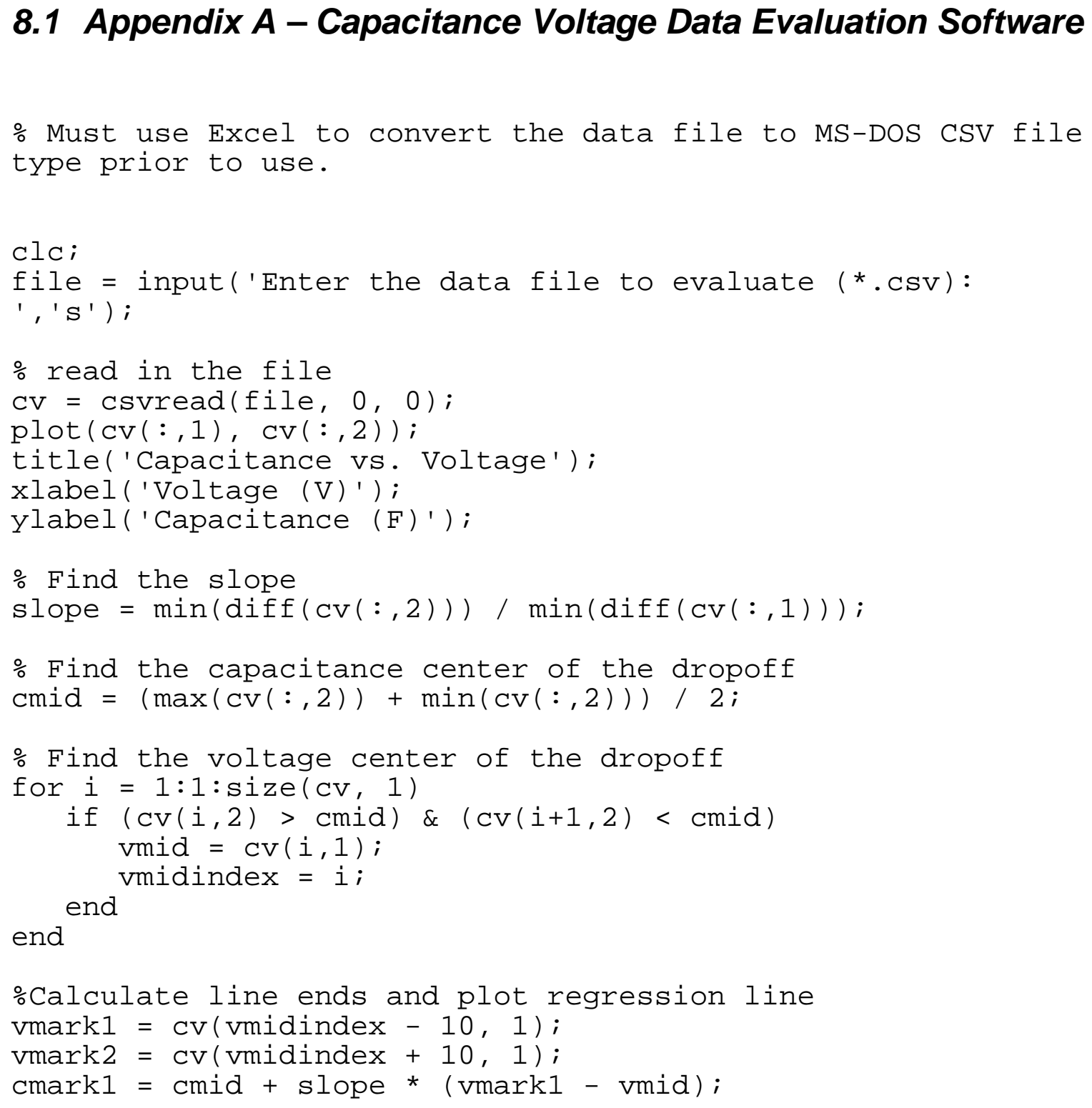




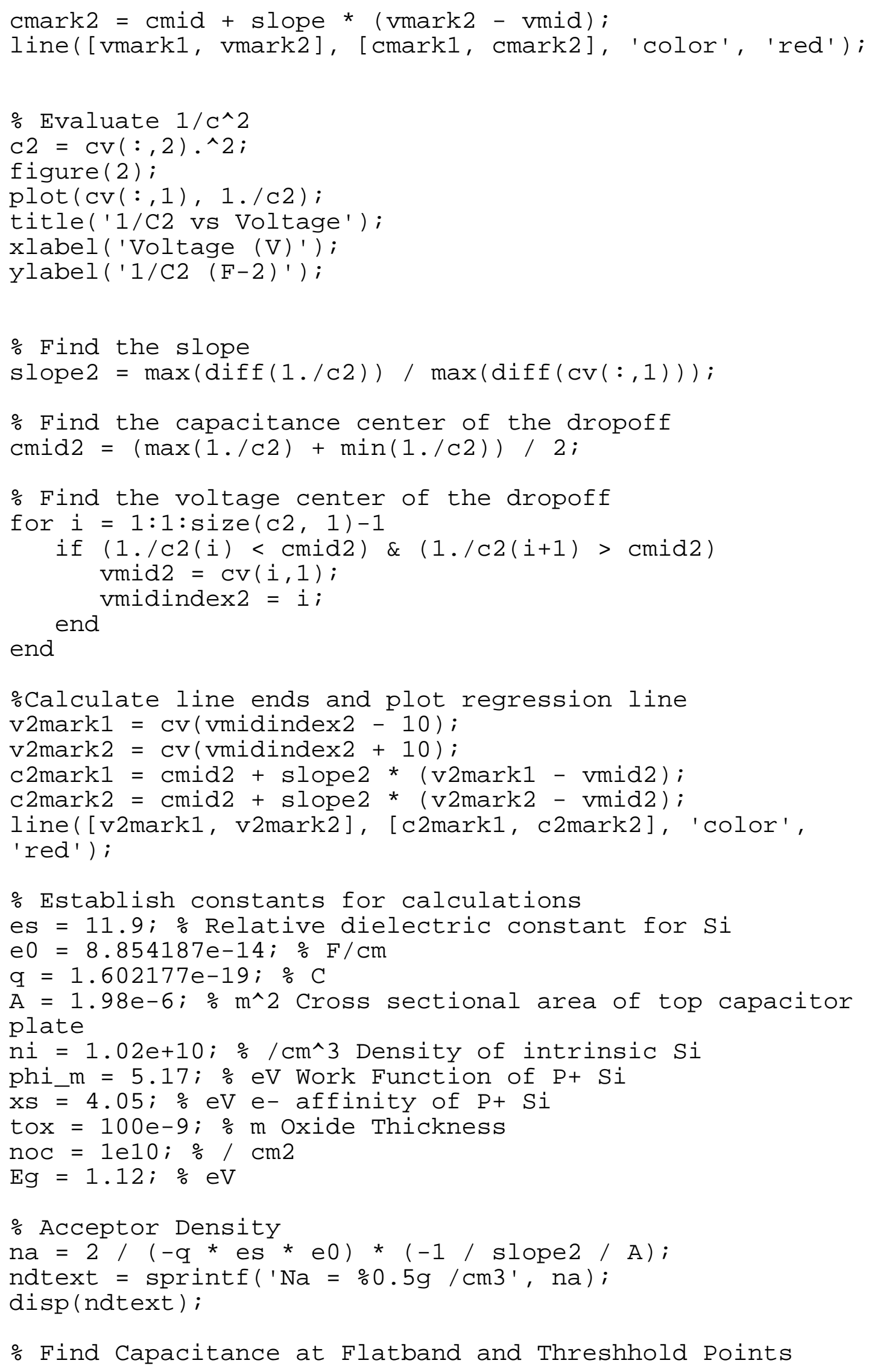




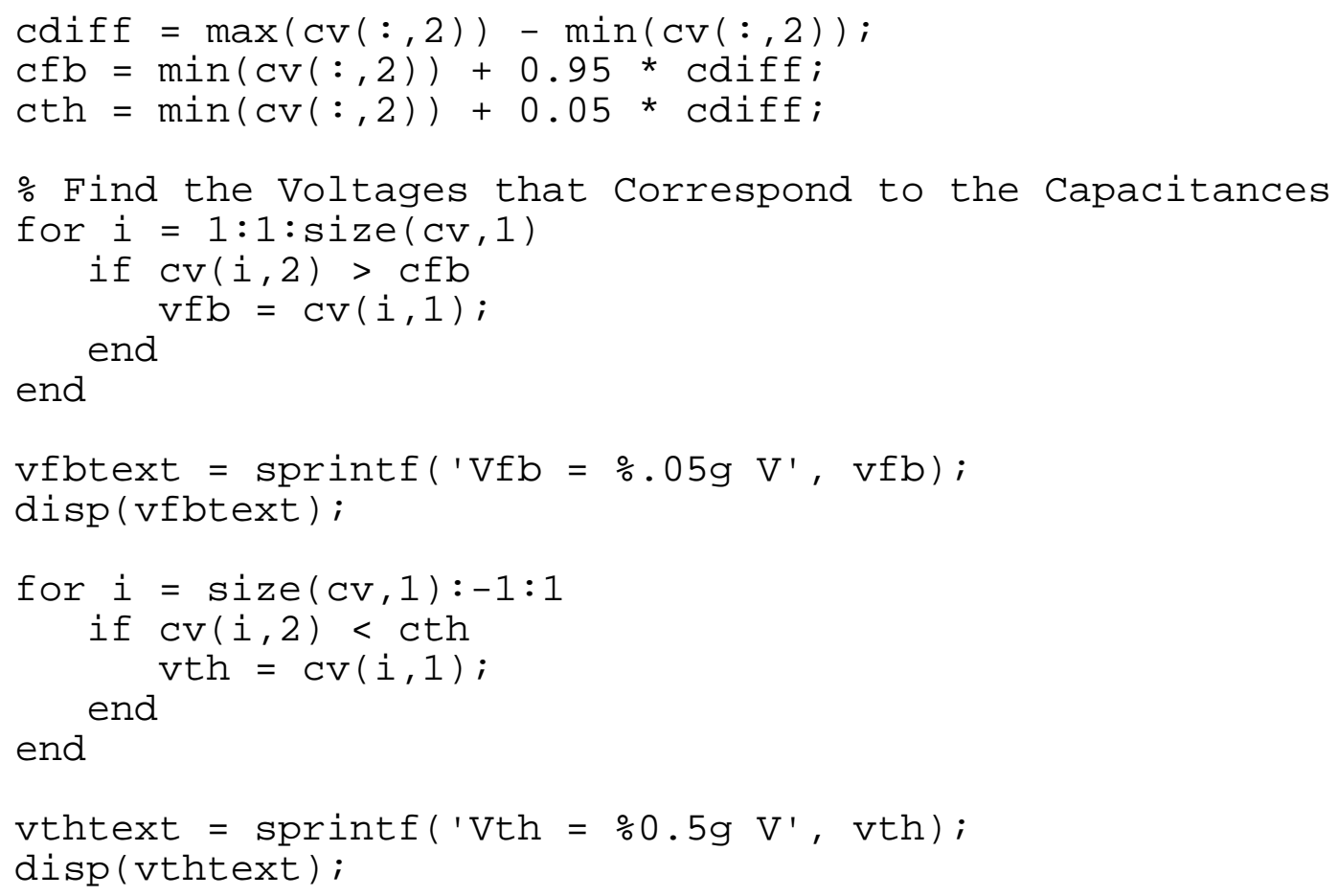




\subsection{Appendix B - Pore Geometry Estimation Software}

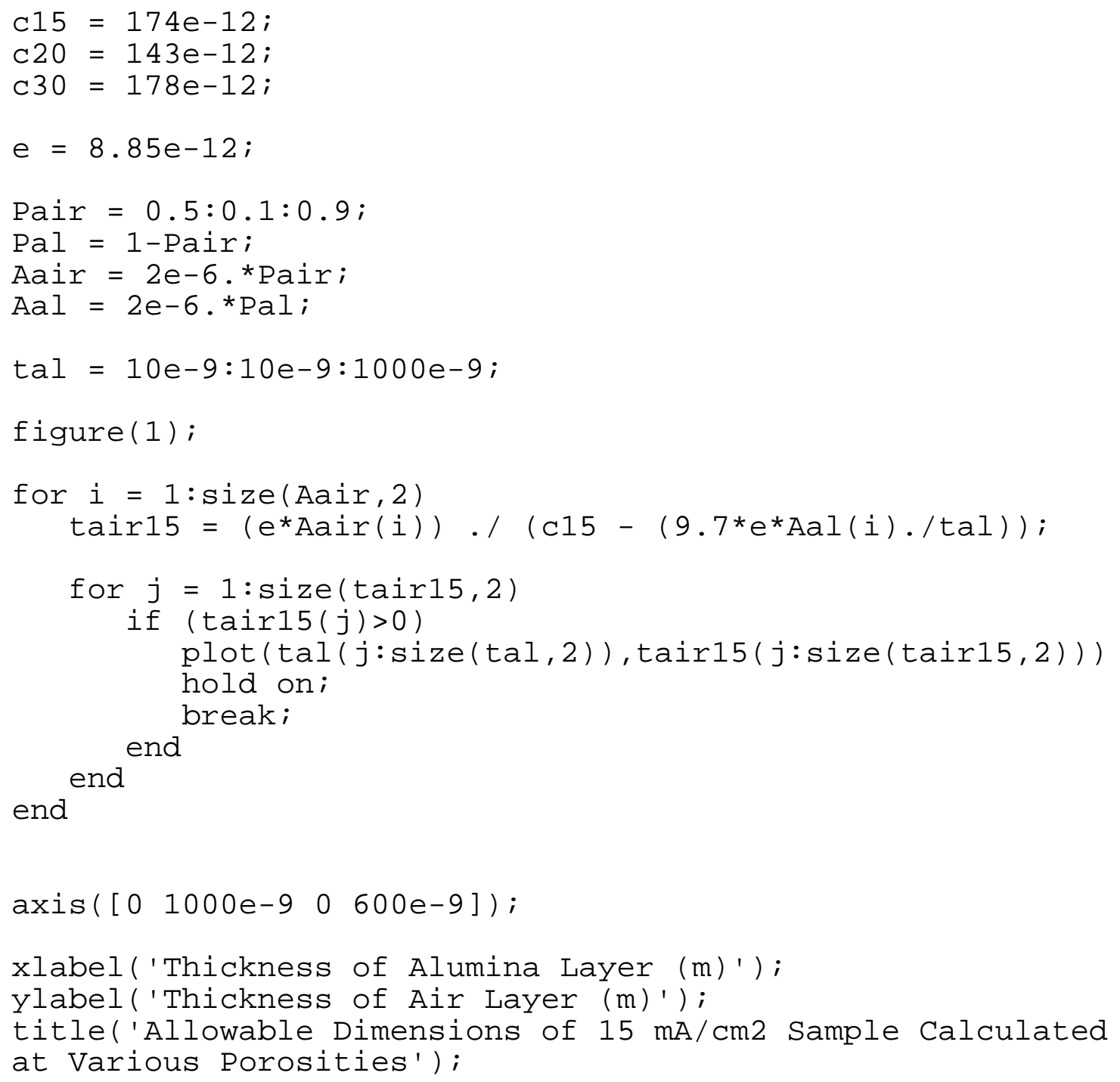




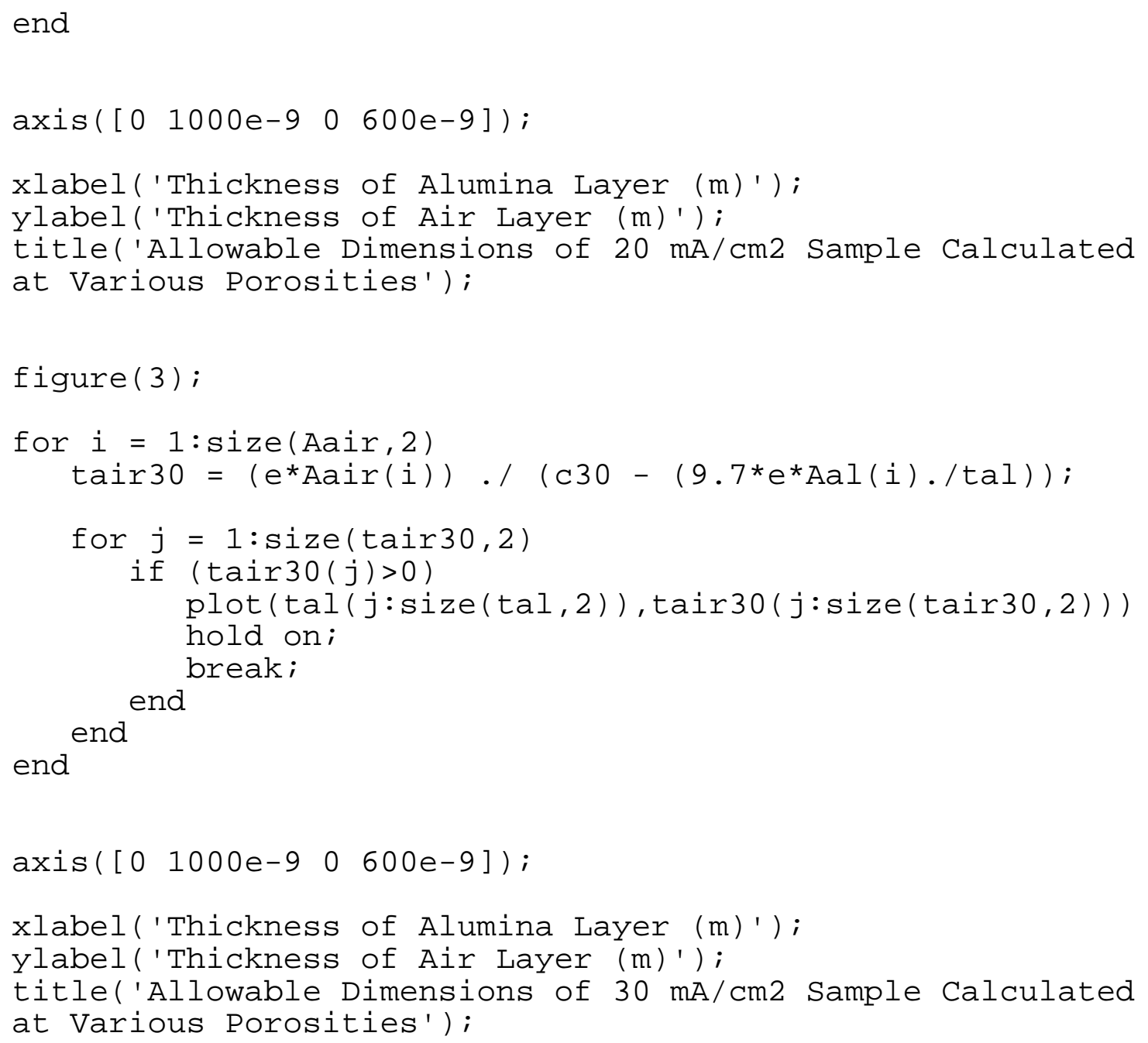




\subsection{Appendix C - Aperture Exposure Immersion Apparatus}

The AEI apparatus was designed and built for use in electrolytic deposition and synthesis of semiconductor nanostructures. Because of the acidic nature of most anodization solutions, Teflon (PTFE) was selected as the material for construction.

Each AEI apparatus consists of two main components - the faceplate and the base. Bases and faceplates may be interchanged to provide more versatility in experiment design. For example, a single base may be used with several faceplates with varying aperture sizes to provide control over the size of the anodized area.

\subsubsection{Base Construction}

The base is constructed from 2" Teflon stock. All cuts are made with a band saw using a 0.250" thick 6 TPI blade. All holes normal to the plane of the stock are drilled with a Craftsman drill press. The angled back contact access hole is drilled with a 1/8" x 6 " long bit in a right angle power drill. To create the recessed area for the back contact table, use a $23 / 8$ " hole saw in a drill press to rough the outline. Remove the excess material by hand with a chisel. Refer to Figure 8.1 for detailed plans. 


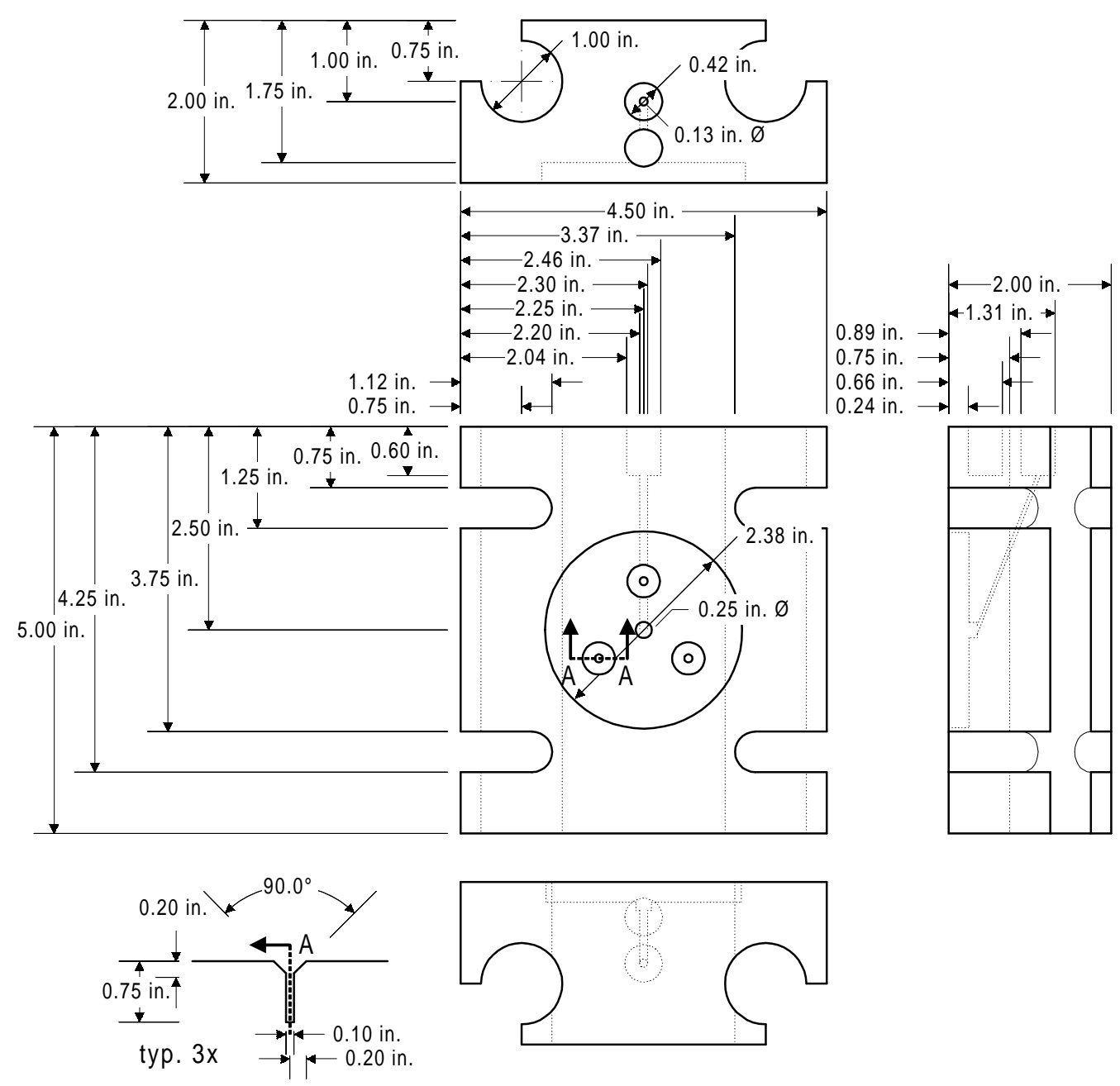

Figure 8.1 - Detailed Construction Plans for AEI Base

\subsubsection{Faceplate Construction}

Faceplates are constructed from 0.500 " Teflon stock. All cuts were made with a band saw using a 1/4" thick 6 TPI blade. The bevel on the edge of the faceplate provides clearance for the wing nuts when they are hinged into position. These cuts are made by tilting the table to $45^{\circ}$. Refer to Figure 8.2 for details. 


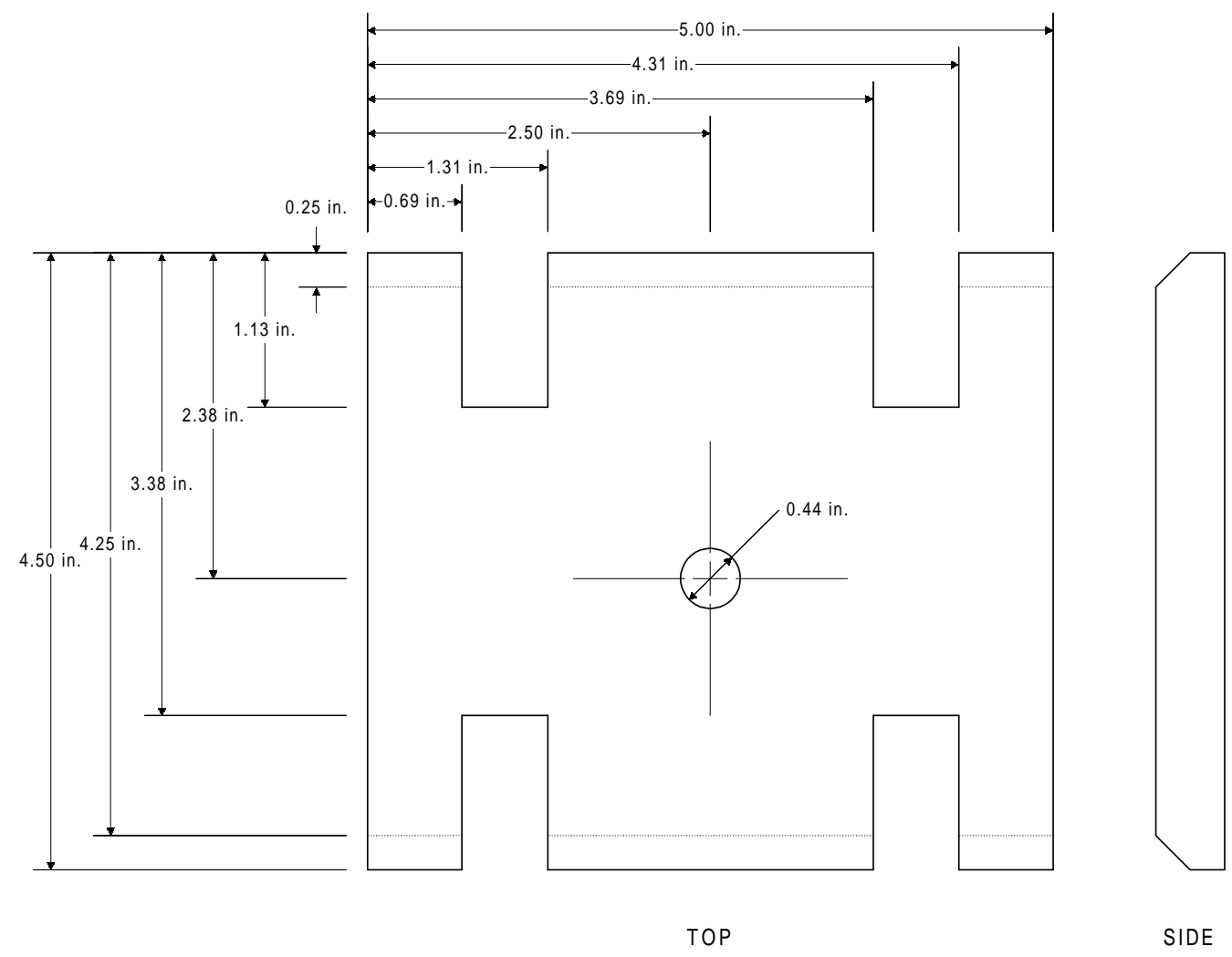

Figure 8.2 - Detailed Construction Plans for AEI Faceplate

Once all cuts are made, the face opposite the bevel is polished to a mirror finish. Fasten well-moistened 220 grit wet/dry sandpaper to a flat surface and polish in a random orbital manner. Rinse the sandpaper and repeat several times until smooth. Repeat the process with 600 grit wet/dry sandpaper until a reflection can be seen.

When polished, dry thoroughly and select a Viton O-ring that is slightly larger than the aperture of the faceplate. Secure the O-ring to the polished side with marine-grade silicone sealant. Use only a small amount of silicone so that it does not cover the O-ring where it will contact the sample wafer. See Figure 8.3 for details. 


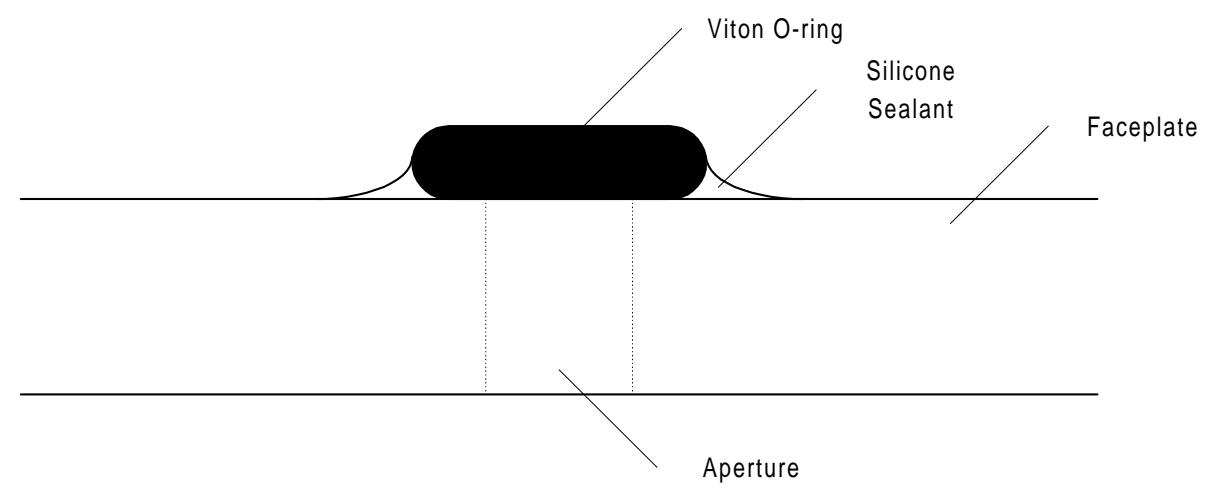

Figure 8.3 - Detail of O-Ring Seating on Faceplate 